\title{
From mine to coast: transport infrastructure and the direction of trade in developing countries
}

\author{
Roberto Bonfatti \\ University of Nottingham \\ Steven Poelhekke \\ Vrije Universiteit Amsterdam, Tinbergen Institute, and De Nederlandsche Bank*
}

January 13, 2017

\begin{abstract}
Mine-related transport infrastructure typically connects mines directly to the coast, a pattern that is most clearly seen in Africa. We estimate the effect of such infrastructure on the pattern of bilateral trade flows. We find that a standard deviation increase in the number of mines over the mean biases a country's pattern of trade flows in favor of overseas trade, to the extent that these mining countries import $56 \%$ less from neighboring countries (relative to overseas countries), than do countries with an average number of mines. However, this effect is reversed for mining landlocked countries, who import relatively more from neighbors. We rationalize this finding through the unequal effect that mines have on a country's network of infrastructure: because the mine-related transport infrastructure connects the coast rather than neighboring countries, it lowers the cost of trading with overseas countries more than with neighbors. In contrast, for landlocked countries trade costs are also lowered with some neighbors through which infrastructure is built to reach the coast. The effect is specific to
\end{abstract}

\footnotetext{
${ }^{*}$ Corresponding author. Email: steven.poelhekke@vu.nl. Views expressed are those of the authors and do not necessarily reflect official positions of De Nederlandsche Bank nor of the Eurosystem of central banks. We are also grateful to Kerem Cosar, Klaus Desmet, Brian Kovak, Torfinn Harding, Oliver Morrissey, Pierre-Louis Vezina, Tony Venables, seminar participants at the EBRD, the Vrije Universiteit Amsterdam, LSE, the Universities of Nottingham, Oxford, Birmingham, Trier, Manchester, Alicante, and Munich, as well as to conference participants at the 2015 CESIfo Global Economy Conference, the 2015 CSAE Conference in Oxford, the 2012 Rocky Mountain Empirical Trade Conference in Vancouver, RCEF 2012 in Toronto, the 2012 EEA Meetings, and the 2012 ETSG. Both authors are also affiliated with OxCarre and CESIfo.
} 
mines and not to oil and gas fields, because pipelines cannot be used to trade other commodities. The effect is robust to measuring the stock of mine-related infrastructure by distance along roads between mines and ports, and to taking into account their relative position to routes used for trade between ports and main cities. We discuss the welfare implications of our results for development, and relate these to the recent surge of Chinese infrastructure investment in Africa.

JEL Codes: F14, F54, Q32, R4.

Keywords: Mineral Resources, Transport Infrastructure, Regional Trade Integration, Gravity Model, Economic Legacy of Colonialism.

\section{Introduction}

Mine-related transport infrastructure typically connects mines directly to the coast, at least in countries where those mineral resources are mostly exported. But if mines are an important determinant of total national investment in infrastructure, a resource-rich country may end up with a transportation network with an interior-to-coast shape, potentially biasing its trade costs in favour of overseas countries relative to neighboring countries. This pattern seems most relevant in Africa. It has often been pointed out that African roads and railways have a markedly interiorto-coast shape, which is historically rooted in the need to export natural resources. Figure 1 illustrates this. The figure presents a map of Africa's best roads, which are also the main arteries through which international trade is channeled. ${ }^{1}$ In many African countries, roads have an interior-to-coast shape with relatively few links connecting neighboring countries. Many such links seem to have been designed primarily to connect the interior of a landlocked country to the coast. There is, however, some degree of variation: for example, resource-rich Guinea or Ghana have a more interior-to-coast shape than Kenya, Tanzania or Namibia. ${ }^{2}$ In addition, resource-rich and landlocked Zambia or Zimbabwe have many good links to the coast, whereas Uganda or the Central African Republic have only one or none. This peculiar shape of African infrastructure is

\footnotetext{
${ }^{1}$ These are "main" or "asphalt" roads, as classified by Vmap0, the USGS National Imagery and Mapping Agency, and the African Development Bank. A picture for railways looks very similar, however we prefer to focus on roads because they are comparatively more important for contemporary African trade. Thirteen countries have no railway at all, and many of the existing railways are in derelict state. In fact, $80 \%$ of non-mineral freight in Africa is transported on Southern African lines (World Bank, 2010, p. 231). See also Jedwab and Moradi (forthcoming) for the relative development of rail and road since colonial times.

${ }^{2}$ In the Online Appendix, we provide a case study of Ghana, a resource-rich country where the colonial transport infrastructure had a clear interior-to-coast pattern, and has persisted to these days.
} 
likely to have influenced Africa's relative trade costs: for example, Limao and Venables (2001) find that poor transport infrastructure in Africa disproportionately penalises intra-African trade (as opposed to trade between Africa and the rest of the world).

The peculiar shape of African infrastructure is often blamed on colonial policies, based on the belief that colonisers cared too much about the colonies' trade in natural resources as opposed to their local and regional trade (e.g. Rodney, 1982, p. 209). They then invested only in the presence of rich resource endowments and even then only in interior-to-coast networks. Africa's interiorto-coast networks are deemed to be ill-suited to promote its regional integration (Sachs et al., 2004, p. 182), which in turn is often seen as a key step towards industrial development (Collier and Venables, 2010). For this reason, the African Development Bank has been promoting an ambitious plan to upgrade Africa's interior-to-interior infrastructure: the overland connections between the African countries (e.g. African Development Bank, 2003, p. 17). ${ }^{3}$

In this paper we test - and provide the first economic evidence in support of - the claim that, in Africa, natural resource abundance is associated with interior-to-coast transportation networks and thus with relative trade costs that favour overseas countries. In particular, we focus on mines and mine-to-coast infrastructure, and test the following two hypotheses. First, African countries export most of their mineral resources overseas, requiring transport infrastructure to connect the mineral-rich regions to the coast. To the extent that such mine-to-coast infrastructure is also usable to trade other goods it will reduce transport costs, and more so for trade with overseas countries (which will always be routed through interior-to-coast connections) than for trade with neighbors (which will, at least in some cases, be routed through cross-border connections, and thus not benefit from the mine-to-coast infrastructure). Thus, our first hypothesis is that more mine-related infrastructure should result in relative trade costs that favour overseas countries over neighbors and in more trade with overseas countries relative to neighbors. Second, we hypothesize that this effect should be weaker (or reversed) for landlocked countries, where the mine-to-coast infrastructure will necessarily cut through some transit neighboring countries, and thus also reduce the cost of trading with these.

We begin by estimating a gravity model of bilateral trade flows between African destinations and worldwide origin countries in 2006 (controlling for importer and exporter fixed effects

\footnotetext{
${ }^{3}$ This was estimated to have the potential to increase overland trade by as much as $\$ 250$ billion over 15 years (Buys et al., 2010).
} 
and a range of standard measures of trade costs), distinguishing explicitly between coastal and landlocked destinations. In our baseline specification we proxy for the amount of mine-related infrastructure with the number of mines in a country. Consistent with our hypotheses, we find that, in coastal countries, a higher number of mines results in less trade with neighboring countries relative to overseas countries, to the extent that coastal countries with a number of mines one standard deviation over the mean import 56\% less from neighbors (relative to overseas countries), than do countries with an average number of mines. However, this effect is reversed for landlocked countries, where a higher number of mines results in more trade with neighbors relative to overseas countries.

The differential trade effect of mines in coastal versus landlocked destinations leads us to attribute this effect to mine-to-coast transport infrastructure, rather than other channels. Several additional tests strengthen our conclusion. First, we use almost 80,000 online MapQuest queries to identify the roads connecting each mine in each country to the coast and to the main container port used for overseas trade, and the roads that connect each main city to the port. We use this information to construct multiple alternative proxies to the number of mines for a country's stock of mine-related infrastructure. First, we measure actual mine-to-port infrastructure by summing all mine-to-port road kilometers. Second, we allow for the possibility that mines do not use the container port but a dedicated port if the mine is close to the coast and far from the port, by summing the minimum of mine-to-port and mine-to-nearest-costal-point road kilometers. Third, for the former measure, we first weigh each mine-to-port route by an index that captures the degree of overlap between the mine-to-port route and all city-to-port routes before summing across mines (the idea being that routes that overlap more should matter more for the overseas trade of the cities). Finally, we do a version of the weighted mine-to-port sum of road kilometers where the shortest route is measured in travel time with the aim of taking road quality into account. All of these yield qualitatively the same asymmetric effect of mine-related infrastructure on the pattern of trade.

Second, we conduct two independent falsification exercises. If mine-to-coast infrastructure is what is driving the trade effect of mines, this effect should disappear when we look at specific types of mineral resources that are unlikely to generate infrastructure usable to trade other goods. We therefore add the number of oil and gas fields to our baseline specification, on the premise that oil and gas, differently from other mineral resources, are mostly transported through pipelines. 
As expected, we find that mines have an asymmetric trade effect while oil and gas fields do not. Furthermore, if mine-to-coast infrastructure is what benefits imports from overseas countries (relative to imports from neighbors) this effect should also apply to imports from non-neighboring African countries (relative to neighbors), which we find it does.

Finally, in further robustness tests we specifically identify trade between the landlocked countries and the coastal countries which they use as transit, instrument the number of mines with discovered deposits, allow for selection bias in the trade data, and test our hypotheses for different years as well as for exports. In all cases we find evidence in favor of our hypotheses. We also run all our regressions for a larger sample of former colonies that includes non-African destinations to show that the effect is not unique to Africa. We find no trade effect of mines in a sample of non-former colonies. This may hint at a colonial legacy explanation for the trade effect of mines: if colonisers only invested in resource-rich countries, and even then only in interior-to-coast networks, and if transportation networks persist over time, you would expect the trade effect of mines to be stronger in former colonies.

Our findings shed lights on the link between natural resource endowments and Africa's peculiar interior-to-coast transportation networks as well as on the impact of such networks on relative trade costs. However, they do not inform us on their impact on absolute trade costs, nor do we know what the historical counterfactual to those networks would have been. We thus cannot evaluate the welfare impact of such networks. Nonetheless, our results on relative trade costs have important implications for development, which should be taken into account when planning future infrastructure investment. We make this point in relation to the different approach that international development agencies and China seem to have taken to African infrastructure investment in recent years.

The paper is related to a growing literature on the economic impact of transport infrastructure. This has looked at the impact of infrastructure on the location of economic activity (e.g., Duranton et al., 2014, for the US; Faber, 2014, for China), long-run economic growth (e.g. Banerjee et al., 2012, for China), and market integration (e.g. Cosar and Demir, 2015, for Turkey; Donaldson, forthcoming, for 19th-century India; Keller and Shiue, 2008, for 19th-century Germany). ${ }^{4}$ We contribute to this literature by investigating the asymmetric market integration effect of natural

\footnotetext{
${ }^{4}$ Michaels (2008) uses the exogenous placement of transport infrastructure as an exogenous source of variation in trade barriers in US counties, and study the effect on the demand for skilled labor.
} 
resource-related transport infrastructure across a large sample of countries.

The paper is also related to the literature on the economic legacy of colonial empires. Recent contributions include Nunn (2008) on the long-run consequences of the slave trade on Africa; Huillery (2009) on the long-run effects of public investment in colonial French Africa; and Iyer (2010) on the comparative long-run impact of direct versus indirect colonial rule in India. We contribute to this literature by looking at the cross-sectional (long-run) trade effect of investment in mine-related transport infrastructure. Although Huilery (2009) and Banerjee et al. (2012) also look at the long-run impact of infrastructure, we test for different hypotheses regarding the impact of mine-related infrastructure on the pattern of international trade. ${ }^{5}$

Finally, the paper is related to the gravity literature on intra-African trade. Limao and Venables (2001) find that, after controlling for standard determinants of trade costs, trade between pairs of Sub-Saharan African (SSA) countries is lower than trade between pairs of non-SSA countries. However, after controlling for a rough measure of the stock of national infrastructure this difference becomes positive. They also find that the negative effect of distance on bilateral trade flows is larger for SSA than for non-SSA pairs. We contribute to this literature by looking at the causes of relatively poor infrastructure connecting the African countries. ${ }^{6}$ Finally, the paper is related to the literature on the resource curse (see Van der Ploeg, 2011, for a recent survey), which has presented various arguments why natural resource booms may not be a great source of domestic growth for developing countries. Our results suggest that they may not be a great source of growth for regional trading partners either, if they are accompanied by an infrastructure-driven re-orientation of trade towards overseas countries (a possibility which we discuss in Section 6 ). ${ }^{7}$

The paper is organized as follows. Section 2 formalises the main hypotheses and embed them in a standard gravity framework. Section 3 discusses data sources and the construction

\footnotetext{
${ }^{5}$ The idea that a country's natural resource production may adversely bias national trade patterns dates back to the so-called "Dependency School" (e.g. Dos Santos, 1970; Amin, 1972). The argument that transport infrastructure played a key role in all this has been made, among others, by Rodney (1982), and Freund (1998). However, to the best of our knowledge, no other paper has systematically tested this with data on mines.

${ }^{6}$ The effect of interior-to-coast transport infrastructure is conceptually similar to that of a reduction in tariffs that is biased in favour of overseas countries. Thus, our paper is related to a literature that has sought to understand whether the interests of developing countries are best served by North-South or South-South trade agreements. For example, Venables (2003) finds that for a medium-income developing country, to sign a custom union with developed countries may be less welfare-enhancing than to sign it with a low-income neighbor, while for the latter the opposite is likely to be true.

${ }^{7}$ Because of these implications, the paper is related to the literature on international growth spillovers (e.g. Easterly and Levine, 1998; Roberts and Deichmann, 2011), and particularly those papers that look at natural resource booms explicitly (e.g. Venables, 2011).
} 
of variables. Section 4 and 5 present the results, and Section 6 discusses their implications and concludes.

\section{Hypotheses and Empirical Strategy}

We begin this section by stating our two hypotheses, and we then explicitly motivate them and operationalise them in the context of a gravity model of trade. Our hypotheses are:

Hypothesis 1: in coastal countries, more mine-related transport infrastructure results in less trade with neighboring countries, relative to trade with overseas countries.

Hypothesis 2: such an asymmetric effect of mine-related transport infrastructure is weaker, or reversed, for the trade between landlocked countries and their trade partners.

To motivate our hypothesis, we start from a standard gravity model specifying trade between country o ("origin") and $d$ ("destination") (see Head and Mayer, 2014, for an overview):

$$
\ln \operatorname{trade}_{o d}=k+\alpha \ln \widetilde{\tau}_{o d}+f_{o}+f_{d}+v_{o d},
$$

where $k$ is a constant, $\widetilde{\tau}_{o d}$ is a measure of all trade costs incurred to trade between $o$ and $d, \alpha$ is a negative coefficient, $f_{o}$ and $f_{d}$ are origin and destination fixed effects, and $v_{o d}$ is an error term. A country can in principle enter both as an origin and as a destination. Our goal is to determine how $\widetilde{\tau}_{o d}$ depends on mine-related transport infrastructure in $d$, for all possible $o .^{8}$

Consider first a world with only coastal countries. This is represented in Figure 2, Panel I, where a destination $d$ imports from $n$ origins, of which $o_{1}, \ldots, o_{5}$ lie on the same continent and $o_{6}, \ldots, o_{n}$ are overseas. Overseas origins are connected to the destination through a sea route that uses port $P$. Suppose a mine $M$ exists in $d$. How will its transport infrastructure affect $d$ 's cost of importing from all $o$ ? Our argument proceeds in three steps.

First, because in developing countries mineral products are mostly exported overseas, M's transport infrastructure is more likely to connect it to $P$, than to the borders with neighboring $o_{1}, \ldots, o_{5}$. In the figure, this is represented by the thicker line connecting $M$ to $P$. Second, the

\footnotetext{
${ }^{8}$ In our empirical analysis, we will also separately look at the effect of mine-related transport infrastructure in $o$, for all possible $d$ (see Table 8).
} 
infrastructure connecting $M$ to $P$ (from now onwards, the mine-to-coast infrastructure) will, in many cases, also be usable to transport goods and will thus reduce the country's overall trade costs. However, since trade with $o_{6}, \ldots, o_{n}$ will always be routed through $P$, whereas trade with $o_{1}, \ldots, o_{5}$ will at least in some cases be more cheaply routed via cross-border connections, the mine-to-coast infrastructure is more likely to reduce the cost of trading with the former group of countries than with the latter. Third, a given stock of mine-to-coast infrastructure may have a stronger effect on transport costs in a small country than in a large one. ${ }^{9}$ In summary, we may expect that coastal countries with more mine-related transport infrastructure per square kilometer should on average face lower costs of trading with overseas countries, relative to neighbors.

Next consider a world in which there also exist landlocked countries (Figure 2, Panel II). Steps 1-3 are still valid to describe the effect of mine-related transport infrastructure on the cost of trading with overseas countries relative to neighboring $o_{1}, o_{2}$ and $o_{5}$. However, there are now two neighbors of the landlocked destination $\left(o_{3}\right.$ and $\left.o_{4}\right)$ with whom trade costs have also been reduced by the mine-to-coast infrastructure that cuts through them. Landlocked destinations will always use at least some of their neighbors as transit. We may then expect that the above-mentioned effect of mine-related transport infrastructure should be weaker in landlocked destinations.

It is reasonable to assume that the more mines a country has the larger and of better quality its stock of mine-related transport infrastructure will be. ${ }^{10}$ Therefore, we use the number of mines per square kilometer in $d, m_{d} / a_{d}$, as our main proxy for the stock of mine-related transport infrastructure per square kilometer (we also construct alternative proxies which we propose in Section 3.3).

Combining these arguments, we relate the mine-related transport infrastructure in a destination country to trade costs, $\widetilde{\tau}_{o d}$, as follows:

\footnotetext{
${ }^{9}$ For example, a 200 kilometer long mine-to-coast road in the Gambia will reach most of the country's population, while a similar road in Nigeria will only reach a small portion of the population.

${ }^{10}$ If mines are scattered throughout the national territory, more of them necessarily implies a larger stock of mine-related infrastructure. If mines are concentrated in a region, more of them may not imply a larger stock, but will still imply a better quality of mine-related infrastructure, since transport infrastructure must be strong enough to withstand higher tonnages of goods traveling across them. In both cases, more mines imply a larger number of trucks and carriages that reach the ports with mining products and that can be used to import goods on their way back.
} 


$$
\begin{aligned}
\ln \widetilde{\tau}_{o d} & =-\delta N_{o d}-\gamma_{1} \ln \frac{m_{d}}{a_{d}} N_{o d}-\gamma_{2} \ln \frac{m_{d}}{a_{d}}\left(1-N_{o d}\right)+ \\
& -\rho L_{d} N_{o d}-\gamma_{3} \ln \frac{m_{d}}{a_{d}} L_{d} N_{o d}-\gamma_{4} \ln \frac{m_{d}}{a_{d}} L_{d}\left(1-N_{o d}\right)+\ln \tau_{o d}
\end{aligned}
$$

where $\tau_{o d}$ is a vector of standard determinants of trade costs, $N_{o d}$ and $L_{d}$ are, respectively, neighbor and landlocked destination dummies, and $\delta, \rho$, and $\gamma_{1} \ldots \gamma_{4}$ are coefficients. We expect $0<\gamma_{1}<\gamma_{2}$, but $\gamma_{3}>\gamma_{4}$ : the stock of mine-related transport infrastructure per square kilometer - as proxied by the number of mines per square kilometer $\left(m_{d} / a_{d}\right)$ - should reduce the cost of trading with overseas countries more than the cost of trading with neighbors, but this differential effect should be weaker for landlocked destinations. In other words, it should be the case that $\gamma_{2}-\gamma_{1}>\left(\gamma_{2}+\gamma_{4}\right)-\left(\gamma_{1}+\gamma_{3}\right)$.

Having constructed an expression for the expected impact of mine-related transport infrastructure on trade costs (2) we can plug this back into our gravity equation (1) and re-arrange to obtain our main regression equation:

$$
\begin{aligned}
\operatorname{lnimp} \operatorname{id}_{o d} & =k+\beta_{1} N_{o d}+\beta_{2} N_{o d} M_{d}+\beta_{3} N_{o d} L_{d}+\beta_{4} N_{o d} L_{d} M_{d} \\
& +\beta_{5} N_{o d} A_{d}+\beta_{6} N_{o d} L_{d} A_{d}+\beta_{7} \ln \tau_{o d}+f_{o}+f_{d}+v_{o d}
\end{aligned}
$$

where $M_{d} \equiv \ln m_{d}$ and $A_{d} \equiv \ln a_{d} \cdot{ }^{11}$ We have included all terms that in (2) do not depend on bilateral variables in the destination fixed effect $f_{d}{ }^{12}$ The first row contains our variables of interests, while the second row are control variables. Our main coefficients of interest are $\beta_{2}$ and $\beta_{4}$, where $\beta_{2}=\alpha\left(\gamma_{2}-\gamma_{1}\right)$, and $\beta_{4}=\alpha\left(\gamma_{4}-\gamma_{3}\right) .{ }^{13}$ We expect $\beta_{2}<0, \beta_{4}>0$, and possibly $\beta_{2}+\beta_{4}>0$ : in coastal countries, more mine-related transport infrastructure (as proxied by the number of mines, $M_{d}$ ) should result in less trade with neighboring countries relative to trade with overseas countries $\left(\beta_{2}<0\right)$, since the mine-related transport infrastructure biases relative trade

\footnotetext{
${ }^{11}$ We could have treated $\ln m_{d} / a_{d}$ as a single regressor, instead of breaking it into $\ln m_{d}$ and $\ln a_{d}$. Indeed, results are robust to using the former specification (see Table 6, column 2). However, we prefer the latter specification because it is more flexible, and allows for an independent effect of area on trade with neighbors. For example, larger countries could import more from neighbors simply because of longer borders. In the empirical analysis, we measure $A_{d}$ as deviation from average, so that $A_{d}=0$ represents the case of a destination country with average size.

${ }^{12}$ That is, the terms $\gamma_{2} \ln \frac{m_{d}}{a_{d}}$ and $\gamma_{4} \ln \frac{m_{d}}{a_{d}} L_{d}$.

${ }^{13}$ The other coefficients can be written as follows: $\beta_{1}=-\alpha \delta, \beta_{3}=-\alpha \rho, \beta_{5}=-\alpha\left(\gamma_{2}-\gamma_{1}\right), \beta_{6}=-\alpha\left(\gamma_{4}-\gamma_{3}\right)$ and $\beta_{7}=\alpha$.
} 
costs in favor of overseas countries. Such an asymmetric effect of mine-related infrastructure should be weaker $\left(\beta_{4}>0\right)$, or reversed $\left(\beta_{2}+\beta_{4}>0\right)$, for the trade of landlocked countries with their trade partners, since in this case the mine-related infrastructure will also reduce the cost of trading with at least some neighbors. Note that $\beta_{2}<0$ is the equivalent of Hypothesis 1, whereas $\beta_{4}>0$ (and possibly $\beta_{2}+\beta_{4}>0$ ) is the equivalent of Hypothesis 2 .

In our main analysis, we focus on Africa. If mines turn out to have an effect on relative trade costs in that region, one possible explanation is that they do so partly because of a colonial legacy: it might be that the colonisers disproportionately cared about the colonies' trade in natural resources as opposed to their local and regional trade. As a consequence, they only invested in the presence of rich resource endowments and even then only in interior-to-coast networks. ${ }^{14,15}$ To investigate this, we split the world into two samples. The first sample comprises of countries which (like Africa) were decolonised recently (after 1900). This includes all of the African colonies plus a number of countries in Asia, the Middle East, and Central America (see Section 3.4 and the Appendix for more details). The second sample comprises of all other countries. If colonial legacy matters for the impact of mines on relative trade costs, we expect the impact of mines to be stronger in the former sample than in the latter. We separately estimate equation (3) in the two samples and compare results.

\section{Data and Variable Definitions}

To estimate the effect of mine-related transport infrastructure on trade we require data on bilateral trade flows between as many countries as possible, a measure of mine-related transport infrastructure, as well as variables that capture bilateral trade costs. The following subsections discuss the source and construction of each variable. Summary statistics are provided in Tables $1-4$.

\footnotetext{
${ }^{14}$ In unreported regressions we found that, in countries that were decolonised relatively recently but not elsewhere, both in 1963 and in 2006 the number of mines is a predictor of kilometer of roads. These regressions controls for population, per capita GDP and area.

${ }^{15}$ One might argue that, in comparison, a benevolent planner might have invested more in resource-poor countries and in a more balanced network for resource-rich countries. Of course, we do not know that (absent colonialism) the African countries would have been managed by benevolent planners. Even more importantly, we do not know that such planners would have behaved any differently than colonisers, given the importance of the overseas natural resource trade for the African economies and their scarce financial resources. These issues are further discussed in Section 6.
} 


\subsection{Trade}

For trade, we rely on the UN Comtrade database which reports all known bilateral trade flows in terms of value between countries in the world based on the nationality of the buyer and seller. ${ }^{16}$ We measure the value of trade at the importing country and use the 2006 cross-section which covers the highest number of countries in Comtrade (particularly for Africa). Even for this recent year, we find that out of 49,506 (223 by 223-1) possible trade flows only $57 \%$ are positive, while the other observations are coded as missing. Within Africa, there are 55 by 54 possible trade flows of which we observe $60 \%$. After taking logs and conditioning on standard control variables, our baseline regressions will be able to include around 6,000 observations where the destination country is in Africa. As is typical with trade data, it is not certain whether the missing observations are missing or if they are in truth zero flows, and they will be lost when taking logs. This may introduce selection bias, but in robustness tests we show that our results are robust to specifically allowing for zeros in trade flows and to using the smaller samples of alternative years.

Tables 1 and 2 present summary statistics (the exact definition of "former colonies" is provided in Section 3.4). Perhaps not surprisingly, landlocked countries tend to import relatively more from neighbors. However, the bulk of imports into landlocked countries still comes from non-neighbors, alleviating the concern that imports from the rest of the world may be re-labelled as imports from the transit country, e.g. due to repackaging or accounting errors. Consistent with the view that Africa is the least internally integrated region in the world, the African countries have the lowest share of imports originating from neighbors. Finally, the African countries tend to import mostly manufactures from non-neighbors, and to export natural resources (defined as goods other than manufactures). In contrast, imports and exports of manufactures stand at about half of total imports and exports to and from neighbors. These findings are supportive of the view that African manufactures are not very competitive in global trade, but may be competitive in local and regional trade.

\footnotetext{
${ }^{16}$ SITC Rev. 2, downloaded on Oct 30th, 2009.
} 


\subsection{Mines as a measure of mine-related infrastructure}

Ideally, a measure of mine-related transport infrastructure should take into account not only the amount of infrastructure, but also its location and quality. However, although data exists on the amount, shape and quality of transport infrastructure, it is hard to know what portions of a network were built to serve the mines, as opposed to general transportation purposes. For this reason, we take a simpler approach and use the number of mines in a destination country $\left(M_{d}\right)$ as our main proxy for that country's mine-related transport infrastructure. As explained in the previous section (see in particular footnote 10), this measure should be a good proxy for the amount and quality of mine-related transport infrastructure in a country. In the next section, we describe various ways in which we refine our main proxy to take into account the actual transport infrastructure connecting the mines to the coast, as well as its location and quality.

The US Geological Survey's Mineral Resources Data System (MRDS) ${ }^{17}$ gives us both the number and the location of active mines. The full database contains 305,832 records, but after extensive cleaning we are left with 20,900 mines. ${ }^{18}$ Within this selection of mines $66 \%$ are located in the US, whereas the remaining 7,122 mines cover 129 countries. Of these, 2,382 are in former colonies and 497 in Africa. Although Africa is rich in mineral deposits relatively few have been exploited. Some countries appear to have no mines. Based on the notion that the existence of subsoil assets - and therefore mines - depends mostly on geology (which is essentially random), we add one unit to the count variable of the number of mines before taking logs, to prevent selection on a sample with only non-zero mines. The second rationale for doing this is that it is unlikely that any country truly has no mine at all, while it is probably due to random measurement error that some mines do not appear in the MRDS data. For example, a total of 18 African countries are reported to have no mines, but 9 of these report exports of ores and metals in $2006 .{ }^{19}$ In Section 4.2 we show that this does not affect our main results.

\footnotetext{
${ }^{17}$ Edition 20090205. Source: http://tin.er.usgs.gov/mrds/.

${ }^{18}$ Our empirical strategy requires that we focus on mines that were active in 2006 (or ceased activity not too long before then, since for these the mine-related infrastructure will still be in place), and for whom we know the location. We thus drop the following records: OPER TYPE is processing plant or offshore; PROD SIZE is missing, small, none or undetermined; WORK TYPE is water or unknown; YR LST PRD was before 1960; DEV STAT is prospect, plant, occurrence, or unknown; SITE NAME is unnamed or unknown; and mines for which the coordinates fall outside their country's mainland. Finally, we drop diamond mines, on the promise that diamonds might be flown out rather than transported through roads.

${ }^{19}$ The remaining 9 include small island states and known smaller mineral exporters such as Chad (natron) and the Central African Republic (gold).
} 
Table 3 presents summary statistics. Landlocked countries tend to have fewer mines than coastal countries, both in absolute terms and per square kilometer. However, in Africa the difference in the absolute number of mines is much smaller, and it is actually reversed for the number of mines per square kilometer.

\subsection{Alternative proxies based on the road network}

We construct four additional proxies that capture to what extent a country's network of transport infrastructure is influenced by mining. These are the sum of mine-to-port road kilometers, the sum of the minimum of mine-to-port and mine-to-nearest-coastal-point road kilometers, and two proxies that weigh each mine according to its position relative to the main cities: one based on road kilometers and one based on travel time. This section explains and motivates each proxy.

First, we obtain from MapQuest's online routing server the route of the shortest road connecting each mine $M_{j}$ to the country's main container port $P$ (which will be the main port of entry for the country's seaborn trade). This is achieved by sending pairs of coordinates to MapQuest's online routing server which returns the route and the distance. We elaborate on the details of these procedures in the Appendix. ${ }^{20}$ The location of the country's main container port (point $P$ ) is derived from the "World Port Ranking 2009" provided by the American Association of Port Authorities (AAPA) and Maersk's website, to track the port used by Maersk Line - the world's leading container shipping company - to import a container from Baltimore (or Shanghai) into the country's capital. This source also gives us the waypoint cities and transit country used for trade by landlocked countries. We then sum across all mines in a country and take logs, $\ln \left(\sum_{j} M_{j} P+1\right) \cdot{ }^{21}$ This first alternative proxy captures the idea that exporting minerals from a mine requires the construction or improvement of a road that connects it to the a port. In the same spirit as our main proxy, it may count the same road more than once if more mines use it, to reflect the fact that the road will be of better quality. Unlike our main proxy, it additionally takes into account the actual amount of infrastructure connecting mines to the port by giving mines that are connected via a longer road (and thus potentially reach more of the country's

\footnotetext{
${ }^{20}$ One could be tempted to use railways to measure distances, but a database of railways provided by Vmap0 (www.mapability.com) shows that $86 \%$ of rail kilometers in Africa connect to roads, while the remaining $14 \%$ have a road within 1 kilometer at the median. Moreover, railways tend to be in poor shape and are not likely to be the main mode of transport for trade (World Bank, 2010).

${ }^{21}$ For all road based measures we add 1 before taking logs.
} 
population) a higher weight.

Second, we also use MapQuest to find the shortest route connecting each mine $M_{j}$ to the nearest coastal point (point $S_{j}$ ) for which we rely on the "Global Self-consistent, Hierarchical, High-resolution Shoreline Database" (GSHHSD) provided by the National Oceanic and Atmospheric Administration (NOAA). ${ }^{22}$ For each mine we then find the minimum of $M_{j} P$ and $M_{j} S_{j}$ and sum across all mines in a country and take $\operatorname{logs}, \ln \left(\sum_{j} \min \left(M_{j} P, M_{j} S_{j}\right)+1\right) \cdot{ }^{23}$ This second alternative proxy captures the idea that mines that are close to the coastline and far from the main container port may well use dedicated ports rather than the main container port, a situation that adds relatively less infrastructure that can be used for general seaborn trade.

Third, we construct a mine impact index to capture the extent to which the mine-related infrastructure is close to routes more frequently used to trade with overseas countries (as opposed to neighboring countries). The basic idea is that mine-to-coast roads that are closer to those routes will affect relative trade costs more, compared to more remote roads: we will then weigh each mine-to-coast road by this measure. We now briefly summarise how the index is constructed: a full explanation is provided in the Appendix. Per each mine $M_{j}$ and city $C_{i}$, and given the country's main container port $P$, the index measures the extent to which the connection $M_{j} P$ used by the mine overlaps with the connection $C_{i} P$ used by the city primarily to trade with overseas countries. ${ }^{24}$ The index takes values between zero and one for each $\left(M_{j}, C_{i}\right)$ combination, where a higher value denotes a greater overlap. In addition, a correction term gives a lower value of the index to mines that are better connected to the nearest coastal point $S_{j}$ than to $P$, in acknowledgment of the fact that those mines might not use $P$ at all. Having calculated an index per each $\left(M_{j}, C_{i}\right)$ combination, we average across population-weighted cities to obtain a mine-specific index $I_{j} .{ }^{25}$ To alleviate the concern that some cities might have emerged because of (and along) the mine-to-coast infrastructure, we weigh cities by 1950 population. ${ }^{26}$

Figure 4 provides an example based on actual data points. For each of four African countries,

\footnotetext{
${ }^{22}$ http://www.ngdc.noaa.gov/mgg/shorelines/gshhs.html

${ }^{23}$ For landlocked destinations, both $S_{j}$ and $P$ will be located in a different country.

${ }^{24}$ We postulate that $C_{i}$ 's trade with overseas countries will more frequently use connection $C_{i} P$ than its trade with neighboring countries based on the logic that (unlike trade with overseas countries) trade with neighboring countries may also use cross-border overland connections to reach $C_{i}$.

${ }^{25}$ That is, we implicitly assume that the share of national imports each route represents is proportional to the population size of the city.

${ }^{26}$ Results are robust to using current (2005) population. The location and population of each country's main cities is taken from the UN's "World Urbanization Prospects" database of urban agglomerations with at least 750,000 inhabitants in 2010, to which we add hand collected city coordinates.
} 
the figure reports the location of mines, main cities and the main container port, as well as the mines' average value of the index. ${ }^{27}$ In the top pair of countries (Mozambique and Egypt), mines receive, on average, a low value of the index ( 0.10 and 0.17 respectively), whereas in the bottom pair (Cameroon and Ghana) they receive a high value (0.98 and 0.60$)$. That is because the mines in the former pair are located faraway from city-port corridors. Furthermore, MapQuest reveals that roads are in place (which are not shown in the figure) that quickly connect the mines to the nearest coastal point, without overlapping with city-port corridors. In contrast, mines in Cameroon and Ghana are located close to city-port corridors and their mine-to-coast infrastructure overlaps substantially with such corridors. Our hypothesis is that the average mine in Cameroon and Ghana should decrease the relative cost of trading with overseas countries more than its counterpart in Egypt and Mozambique.

Having calculated the mine-specific index $I_{j}$, we now weigh each distance $M_{j} P$ by $I_{j}$, before summing across mines and taking logs to obtain our third alternative proxy of mine-to-coast infrastructure, $\ln \left(\sum_{j} I_{j} M_{j} P+1\right)$. Relative to our first alternative proxy, our second and third alternative proxies additionally take into account the location of the mine-related transport infrastructure.

Finally, the fourth alternative proxy follows the methodology of the third but uses travel time rather than kilometers as a unit of distance to calculate the shortest routes and is denoted as $\ln \left(\sum_{j} I_{j}^{\text {time }} M_{j} P^{\text {time }}+1\right)$. This final alternative proxy additionally attempts to measure the quality of the mine-related transport infrastructure more directly.

\subsection{Control variables}

We always control for a broad set of standard determinants of trade costs, taken from Head et al. (2010). ${ }^{28}$ These are $\ln$ distance, the natural log of distance between countries; Shared language, a dummy equal to one if both countries share a language; Shared legal, a dummy equal to one if both countries share the same legal origin; ColHist, a dummy equal to one if both trading partners were once or are still (as of 2006) in a colonial relationship; RTA, a dummy equal to one if both

\footnotetext{
${ }^{27}$ For illustrative purposes only, we have reported the closest coastal point to the midpoint of mines, and not the various mine-specific $S_{j}$ that we use in the computation of the index.

${ }^{28}$ The data in Head et al. (2010) stop in 2006. When running regressions for 2007 and 2008 in our robustness section, we use the Regional Trade Agreements Database from Egger and Larch (2008) to update the RTA variable and Wikipedia searches to update Both WTO, Shared currency and ACP.
} 
trading partners belong to a regional trade agreement; Both WTO, a dummy equal to one if both are members of the WTO; Shared currency, a dummy equal to one if they share a currency; and $A C P$, which is a dummy equal to one for trade between EC/EU countries and members of the 'Asia-Caribbean-Pacific' preferential tariff agreement for former European colonies.

In addition, we construct controls for Shared emp, one colonizer and Shared emp, none colonizer, which are dummies equal to one if the both trading partners were once part of the same empire, and, respectively, one of the two or neither or them was the coloniser. We interact each of these two variables with the neighbor dummy. These interactions control for the possibility that colonisers built especially good infrastructure connecting them to a neighboring colony, or connecting two neighboring colonies. The Linder variable is the absolute difference in GDP per capita between trade partners and captures the idea due to Linder (1961) that countries with similar GDP per capita tend to trade more intensively with each other, because the overlap between their production and consumption goods is larger. ${ }^{29}$ It could be that countries with mines and higher natural resource export revenues start importing more sophisticated products through an asymmetric income effect on consumption. On average, such goods will be produced in countries that are not neighbors, or at least from the perspective of many African countries. The Linder variable is included to control for this possibility.

To construct the empire dummies and to be able to split the World sample of countries into former colonies and non-former colonies, we need to define former colonies. We start from the definition by Head et al. (2010) who consider a former colony a country that was colonized and obtained independence after 1900. This seems an appropriate definition for our purposes since we do not expect colonial investment to still matter in countries that became independent too long ago (such as the USA). We further refine the definition by Head et al. (2010) by excluding those countries that were only colonized by a neighbor since we do not expect colonial infrastructure to have an interior-to-coast shape in those cases. ${ }^{30}$

\footnotetext{
${ }^{29}$ We thank an anonymous referee for suggesting this control variable.

${ }^{30}$ For robustness, we have run all our specifications using both the broader Head et al. (2010) definition, as well as a third, even narrower definition. See the Appendix for further details.
} 


\section{Baseline results}

In this section, we report our estimates of equation (3). Our main coefficients of interest are $\beta_{2}$ and $\beta_{4}$. Based on Hypothesis 1 , we expect $\beta_{2}<0$ : in coastal countries, more mine-related transport infrastructure (as proxied by the number of mines, $M_{d}$ ) should result in less trade with neighboring countries relative to trade with overseas countries. Based on Hypothesis 2, we expect $\beta_{4}>0$ : in landlocked countries, such an asymmetric effect of mine-related transport infrastructure should be weaker. In addition, if $\beta_{2}+\beta_{4}$ is found to be not significantly different from zero (or positive), the effect of mine-related transport infrastructure disappears in landlocked countries (or is reversed). To investigate the latter point, we always report at the bottom of tables marginal effects of $M_{d}$ on trade with neighboring countries by landlocked status (this is equivalent to $\beta_{2}$ for $L_{d}=0$, to $\beta_{2}+\beta_{4}$ for $L_{d}=1$ ). In addition, by taking the marginal effect to $N_{o d}$ we may also find that the border effect for coastal mining countries is negative. These effects are unlikely to be due to potential (asymmetric) income effects from mineral extraction (e.g., African countries with more mines consuming a larger number of sophisticated goods produced overseas) because we always control for the Linder variable. ${ }^{31}$ The raw data in Tables 1 and 3 show that regions with more mines tend to import more (which is probably an income effect) and that landlocked countries import a higher share from neighbors. Our regressions will uncover if the share of imports from neighbors is decreasing in the number of mines for coastal countries, but less so for landlocked countries.

\subsection{The trade effect of mines}

Table 5 reports results for each of three samples. The first column focuses on African destinations and the next two columns split the world into destinations that were former colonies and destinations that were never colonies or have gained independence before 1900. Note that we define former colonies as countries that were colonised by an overseas power, which excludes for example members of the former Soviet Union. The trade effect of mines should be more visible in Africa and in former colonies thus defined. The transport infrastructure of these countries will be more heavily shaped by colonial transport infrastructure, which in turn was mostly designed to export natural resources.

\footnotetext{
${ }^{31}$ To further rule out this alternative channel, we conduct two falsification exercises in Section 5.
} 
We find the usual determinants of trade: it decreases in distance and increases in countrypair characteristics that make trade easier such as a common language, legal origin, a former colonial relationship, membership of regional trade agreement and the WTO, sharing a currency (although it changes sign for non-former colonies) and membership of Asia-Caribbean-Pacific (ACP) treatment of imports into the European Union. ${ }^{32}$ Distance and a shared colonial history matter more for African destinations. Finally, the Linder hypothesis is most apparent among African destinations and former colonies.

Hypotheses 1 and 2 are strongly confirmed in the case of African destinations. We find that more mine-related transport infrastructure (as proxied by the number of mines) changes the pattern of trade flows of coastal countries in favor of overseas countries $\left(\beta_{2}<0\right)$. This effect is large: coastal countries with a number of mines one standard deviation over the mean (about equal to a doubling) import $56 \%$ less from neighboring countries (relative to non-neighbors), than do countries with an average number of mines. ${ }^{33}$ The effect is weaker for landlocked countries $\left(\beta_{4}>0\right)$ : in fact, we find that the effect of mines is reversed $\left(\beta_{2}+\beta_{4}>0\right)$. Again, the effect is large: landlocked countries with a number of mines one standard deviation over the mean import 58\% more from neighboring countries (relative to non-neighbors). ${ }^{34}$ Here we treat all neighbors as potential transit countries and do not assume that each country has one specific transit route. Further down, in Section 5, we attempt to identify specific transit countries. For example, Uganda's main transport infrastructure crosses Kenya to reach the sea: but then these should decrease the cost of importing from Kenya, and also from overseas countries.

When we split the sample in former colony destinations and non-former colonies (columns 2 and 3 of Table 5, we find that Hypothesis 1 and 2 are only confirmed in the case of former colonies: only they import relatively less from neighbors if they have more mines $\left(\beta_{2}<0\right)$; moreover, only

\footnotetext{
${ }^{32}$ All African destinations are members of ACP.

${ }^{33}$ Using Tables 4 and $5:-56 \%=1.29 / 1.35 *-0.587$.

${ }^{34}$ Using Tables 4 and $5: 58 \%=1.29 / 1.35 * 0.606$. The effect of mines on landlocked countries may seem large, but this can easily be rationalized. First, the infrastructure connecting the landlocked country to a transit neighbor improves $100 \%$ of the route, whereas it only improves a small percentage of the route connecting the landlocked country to overseas countries. Second and third, the mine-to-coast infrastructure also improves the domestic infrastructure of the transit country (whereas it does not affect the domestic infrastructure of overseas countries), and it does so in a very specific way (along the route that heads for the landlocked country). The latter two factors are likely to be particularly important in the case of Africa, where transportation infrastructure is, in general, extremely poor.

Finally, we experimented with adding interactions with the number of mines in the trade partner country (the terms $N_{o d} M_{o}, N_{o d} L_{o}$ and $N_{o d} L_{o} M_{o}$ ), although these should not correlate systematically with the number of mines in the destination country. These estimates of our main effects are significant, while not significantly different from those in Table 5.
} 
in former colonies, this effect is weaker for landlocked countries $\left(\beta_{4}>0\right)$, to the point that it disappears $\left(\beta_{2}+\beta_{4}\right.$ not significantly different from zero). ${ }^{35}$ These results may indicate a link between the trade effect of mine-related transport infrastructure and colonial legacy: if colonisers only invested in resource-rich countries, and even then only in interior-to-coast networks, you would expect the trade effect of mines to be stronger in countries where colonial policies were active until more recently. ${ }^{36}$ Note that coefficients are larger for the African sample than for the broader former colonies sample: this squares well with our prior that, in Africa, mines were an especially important determinant of total national investment in infrastructure (see Section 1).

Is it still the case that countries that share a border trade relatively more with each other ( $\partial \ln$ (bilateral trade) $\left./ \partial N_{o d}>0\right)$ ? The coefficient, its variance, and the covariance between $N_{o d} M_{d}$ and $N_{o d}$ (or $N_{o d} L_{d} M_{d}$ and $N_{o d} L_{d}$ for landlocked countries) determine a range of $M_{d}$ for which the African countries do not import significantly more from neighbors (relative to non-neighbors). Figure 3 summarizes this relationship. The figure plots the marginal effect of being neighbors on trade as a function of the number of mines in the destination country, by landlocked status, for a country of average size in terms of land area $\left(A_{d}=0\right)$. As we increase the number of mines, the marginal effect of $N_{o d}$ in coastal countries decreases, to the point that a country of average size with more than 14 mines $(=\exp (2.7))$ trades significantly less with neighbors than with non-neighbors. In contrast, the marginal effect of $N_{o d}$ increases for landlocked countries and all landlocked countries trade significantly more with neighbors than with non-neighbors.

Because trade flows are bilateral, an equivalent interpretation of our results is that if a country has many mines, its neighbors export less to it relative to overseas countries, than if it had fewer mines. In other words, a country's mining boom does not imply that this country will spend as much of the extra income on its neighbors' exports (relative to other countries' exports), as one might have expected at pre-existing trade costs: it will actually spend less than that. This effect is likely to persist for a long time, given that once the boom is over, the infrastructure

\footnotetext{
${ }^{35}$ Results for the non-former colonies sample are unaffected by removing the US, which as explained above is an outlier for its very large number of mines.

${ }^{36}$ Alternative explanations for these findings are that, compared to non-former colonies, former colonies are countries for which the overseas natural resource trade is more important, or countries that face weaker financial constraints. Indeed, our sample of non-former colonies includes OECD countries with good connections to all neighbors and trade partners. The marginal mine does not influence their infrastructure much, even if the country is landlocked (such as Austria and Switzerland). Note however that result column 1 are robust to dropping OECD countries from the sample of non-former colonies (the remaining countries including most of Latin America and Central Asia).
} 
will have changed in a way that benefits overseas countries relatively more. Without investment in more cross-border infrastructure mining does not promote exports originating in neighboring countries, or the emergence of local value chains, as much as would be possible with a more balanced infrastructure.

So far, we have proxied for the mine-related transport infrastructure using the number of mines. Since it is not easy to imagine many reasons - other than mine-to-coast infrastructure - why mines should reduce relative imports from neighbors in coastal destinations $\left(\beta_{2}<0\right)$, but much less so when the destination country is landlocked $\left(\beta_{4}>0\right)$, these results provide suggestive evidence in favor of our hypotheses. We next turn to alternative measures of minerelated transport infrastructure.

\subsection{Alternative measures of mine-to-coast infrastructure}

In this section we present results based on alternative measures of mine-related transport infrastructure and show that our results are highly robust. We begin by considering alternative ways in which our main proxy for mine-related infrastructure (the number of mines) may enter the regression, and we will then consider the four alternative proxies discussed in Section 3.3. We focus in the rest of the paper on the African sample only. The Online Appendix reports all regressions for the broader sample of former colonies, and results are qualitatively very similar.

The first set of results is reported in Table 6, columns 1-5. We suppress the control variables from now on, although they are always included, and focus on the interaction variables of interest. For comparison, column 1 repeats the baseline result for the Africa sample. In column 2 we do not control for an interaction with land area separately, and measure $M_{d}$ as the log of the number of mines per (million) square kilometers (that is to say, the term $\ln \left(m_{d} / a_{d}\right)$ in eq. 2 is entered as a single regressor). ${ }^{37}$ Because we do not add one to countries with no mines, we loose one-third of the observations. Even for this smaller sample we still find a negative marginal effect of mines in coastal countries on relative trade with neighbors. The positive marginal effect of mines in landlocked countries is now not significantly different from zero. The third column treats $M_{d}$ as a count variable that includes zero values and scales by area $\left(m_{d} / a_{d}\right.$ entered as a single regressor), while column 4 does not scale by area and includes separate area interactions instead $\left(m_{d}\right.$ and $a_{d}$

\footnotetext{
${ }^{37}$ The controls are the same used in Table 5 , except that in columns 2 and 3, the area interactions are not included.
} 
entered separately). We still find the same pattern. In column 4, each additional mine reduces the relative trade with neighbors by $1.9 \%$ for coastal countries. Landlocked countries import $5.1 \%$ more from neighbors (relative to non-neighbors) with each additional mine. Although our results are robust to using these alternative measures, we prefer to take logs in our main analysis, in keeping with the log-linear gravity model and to allow for a more realistic concavity in the effect of mines on infrastructure.

In columns 5-8 of Table 6 , we turn to our alternative proxies of mine-related infrastructure. In column 5 we measure infrastructure more directly by summing the kilometers along actual roads that connect each mine to the port $\left(\sum_{j} M_{j} P\right)$. The summation captures the idea that even if two mines use one road, we expect the road to be of better quality. For example, heavier traffic requires stronger roads and bridges and mines which require a longer road should have a bigger effects on relative trade costs. ${ }^{38}$ The results are overall very stable but more nuanced: a standard deviation increase in mine-to-port road kilometers in coastal countries reduces relative trade with neighbors by $15.4 \%$, and increases it by $11.4 \%$ for landlocked countries. ${ }^{39}$

Thus far we have implicitly assumed that all mine-related infrastructure overlaps in the same way with city-port corridors, the route used by consumers to trade with overseas countries. This is not necessarily true for mines that export through dedicated ports, for example when they are located close to the coast but far away from the country's main container port. Column 6 therefore measures $M_{d}$ as the sum of the minimum distance along roads of the mine to the port and the mine to the closest point on the coast $\left(\sum_{j} \min \left(M_{j} S_{j}, M_{j} P\right)\right)$. The result is nevertheless very similar to column 5. Next, we turn to the mine impact index $I_{j}$. This provides a more accurate measure of the extent to which each mine-to-coast road should affect relative trade costs. Furthermore, it provides us with an exogenous source of variation: if exploration efforts do not differ much within a country then the location of mines is determined by exogenous geology; in turn, this implies that the necessary infrastructure is also placed exogenously, which helps us identify the impact of mine-to-coast infrastructure on trade. The result is presented in column 7 , where distances are measured in terms of kilometers along actual roads $\left(\sum_{j} I_{j} M_{j} P\right)$ and in column 8 where distances

\footnotetext{
${ }^{38}$ The partial correlation between $M_{d}$ defined as the $\log$ of the number of mines and the log of the sum of mineto-coast road kilometer (controlling for GDP per capita, area, and landlockedness) is $81 \%$ and a simple regression (not shown) suggests that a doubling of the number of mines leads to $90 \%$ more mine-to-coast road kilometer. We additionally tried to scale by the distance between the origin and destination country, but we find that this does not change the conclusion.

${ }^{39}$ Using Tables 4 and $6:-15.4 \%=4.02 / 5.48 *-0.210$ and $11.4 \%=4.02 / 5.48 * 0.156$.
} 
are based on travel time $\left(\sum_{j} I_{j}^{t i m e} M_{j} P^{\text {time }}\right)$. The sign of the coefficients is unchanged, which underscores the robustness of this finding. In terms of magnitudes, a standard deviation increase in index-weighted mine-to-port road kilometers in coastal countries reduces relative trade with neighbors by $14.4 \%$, and increases it by $11.6 \%$ for landlocked countries. For travel time, the effects are $-8.4 \%$ and $+7.5 \%$, respectively. The difference in magnitude suggests that marginal roads are of relatively poor quality which take more travel time and reduce trade costs by less than is suggested by simple road kilometers alone. Nevertheless, this magnitude is economically meaningful and similar to a $4.7 \%$ increase in distance between trade partners, ${ }^{40}$ or more than half the effect of a shared legal origin, everything else equal.

Overall, Table 6 presents consistent evidence in favor of our hypotheses. Mine-related transport infrastructure, measured in a number of different ways, decreases trade costs in an asymmetric way: trade costs between coastal countries and the rest of the world decline relative to trade costs with neighbors, but this effect disappears or is even reversed for landlocked countries. The former result could provide an explanation for relatively limited intra-African trade.

\section{Additional results and robustness}

In Table 7 we perform additional tests of the robustness and causality of our main finding. For comparison, column 1 again presents the baseline results using the number of mines as a proxy for mine-to-coast infrastructure.

Transit country. Column 2 allows for a specific relationships between landlocked countries and their transit neighbor. We have so far been agnostic about which neighboring country of a landlocked country is the transit country, since this may depend on the type of trade and may be endogenous to the number of mines. We now use major rail connections and data from the Maersk container shipping line to find for each landlocked destination the waypoints and transit port used. We then define a dummy $T L_{d}$ which is equal to one if the destination is landlocked and the origin is used for transit by the landlocked country. ${ }^{41}$ Column 2 replaces the landlocked

\footnotetext{
${ }^{40} 4.7 \%=8.4 \% / 1.785$, where the latter coefficient is taken from Table 5.

${ }^{41}$ More in detail, we follow a two-step procedure to construct the dummy $T L_{d}$. First, we enquire with Maersk Line (http://www.maerskline.com) about the route they use to send a container from Baltimore (or Shanghai) to the landlocked country's capital. This yields the African port of call, and thus the transit neighbor used by Maersk. We then set $T L_{d}=1$ for imports of a landlocked country from that particular neighbor. Second, using data on African railways (from Wikipedia) we also set $T L_{d}=1$ for imports of a landlocked country from neighbors to which it is connected through a railway. This procedure yields the following results (in parenthesis are transit countries):
} 
dummy $L_{d}$ with the dummy $T L_{d}$. In terms of significance and magnitude the result is quite similar and robust to this exercise. ${ }^{42}$

Oil $\&$ gas fields. A natural falsification exercise is to investigate whether oil and gas fields have a similar trade effect to that of mines. While the asymmetric income effect (e.g., African countries with more mines consuming a larger number of sophisticated goods produced overseas), as well as yet another alternative channel whereby African countries with more mines import more mining machinery from overseas, should be at play for oil and gas fields as well, the infrastructure channel should not. The infrastructure channel relies on the assumption that the mine-to-coast infrastructure can be used not only to export minerals but also to trade a broad set of commodities. But while metals and other non-hydrocarbon minerals are mostly transported through roads and railways, oil and gas are mostly transported through pipelines. Clearly, the former may also be used for trade, while the latter cannot. ${ }^{43}$ Thus, if the trade effect is due to those alternative channels, it should be there for both mines and oil and gas fields. If it is due to mine-to-coast infrastructure it should be there for mines only. We therefore extend the baseline regression with a measure of oil and gas fields. We use data from Horn (2003), who reports 878 on- and offshore oil and gas fields with a minimum pre-extraction size of 500 million barrels of oil equivalent including year of discovery from 1868-2003, geographic coordinates and field size measures. This data set builds on previous data sets (e.g. Halbouty et al. 1970) and attempts to include every giant oilfield discovered around the world. Oil, condensate and gas are summed, with a factor of 1/.006 applied to convert gas trillion cubic feet to oil equivalent million barrels. We define $O G_{d}$ as the log of the number of fields plus one, similarly as we did for mines.

Results are reported in column 3 of Table 7 . Note that we control for all control variables including the Linder variable, which captures the absolute difference in GDP per capita between

Botswana (South Africa, Zimbabwe); Burkina Faso (Ivory Coast); Burundi (Tanzania); CAR (Cameroon); Chad (Cameroon); Ethiopia (Djibouti); Lesotho (South Africa); Malawi (Mozabique); Mali (Senegal); Niger (Benin); Rwanda (Tanzania); Swaziland (South Africa); Uganda (Kenya); Zambia (Mozambique, Tanzania, Zimbabwe); Zimbabwe (Botswana, Mozambique).

${ }^{42}$ One might have expected that the marginal effect of mines on the landlocked countries' relative trade with neighbors should be higher when we single out transit neighbours, compared to when we treat all neighbors the same. Note however that our procedure to identify transit countries may well label as non-transit some neighbors that are transit in reality. In addition, landlocked countries with more mines tend to have more transits according to our definition. If the marginal effect of $M_{d}$ on total trade with transit countries (relative to non-transit) is decreasing, we would be biasing our coefficient downwards by calculating its average effect over a larger number of transits in countries with higher $M_{d}$. Because of this endogeneity in the number of transit countries, we prefer to look at the average effect across all neighbors (whose number is presumably exogenous) in the main analysis.

${ }^{43}$ Pipelines may have an effect through the construction of maintenance and access roads, but we expect this to be small. 
countries and should capture any asymmetric income effect that leads to more imports from overseas markets. We do not find an effect of oil and gas fields and it does not explain away the negative interaction of mines. ${ }^{44}$ Note that none of the landlocked African countries has major oil \& gas fields. In the Online Appendix we show that the same results hold for a larger sample of former colonies where the latter interaction can be included. The fact that mines remain significant but oil and gas fields do not, is strong additional evidence in support of the infrastructure hypothesis, and against the alternative channels described above.

$I V$ deposits. In column 4 of Table 7 we instrument for the number of mines using data on the number of known mineral deposits. Proprietary data acquired from Minex Consulting provides the number of known mineral deposits in each country in Africa, as of today. We use this as an instrument for the number of mines that have been or are active since 1960. We assume that exploration up to today, conditional on current income per capita and landlocked status, has only randomly delivered deposits because underground geology is exogenous. The number of deposits predicts the current number of mines well (given the high F-test), but not perfectly. This is because some deposits were never developed and some large ones resulted in more than one mine. The net effect is a coefficient below one. ${ }^{45}$ The main pattern is robust to this IV strategy: coastal countries with more mines import relatively less from neighbors, and this effect is weaker (to the point that it disappears) for landlocked countries.

Same continent. A second falsification test further helps to rule out alternative channels. If our results were driven by the fact that African countries with more mines spend more on sophisticated goods or mining machinery produced in developed countries, then those African countries should be importing relatively less not only from neighbors, but also from non-neighboring African countries (since the latter typically do not produce those sophisticated goods or machinery). Instead, if our results were driven by infrastructure, those non-neighbouring African countries should not be relatively penalised, since they also benefit from the mine-to-coast infrastructure. ${ }^{46}$

\footnotetext{
${ }^{44}$ Since the data on oil and gas fields also includes the field's pre-extraction size in millions of barrels of oil equivalent, we also experimented with redefining $O G_{d}$ as the $\log$ of one plus the volume of reserves in the country. This led to qualitatively identical results. However, pre-extraction field size is probably only a rough measure of current field size.

${ }^{45}$ First stage of [4] is a cross-country regression of $M_{d}$ on (with coefficient between brackets and standard errors between square brackets) the $\log$ of the number of deposits $\left(0.856^{* * *}[0.100]\right.$, landlocked status $(-0.403[0.253])$, and $\log$ GDP per capita (0.228*** [0.081]), using 45 observations and giving an R2 of 0.646.

${ }^{46}$ In other words, in the alternative story, relative to an African country with fewer mines, Ghana should not only be importing less from Ivory Coast relative to Germany, but also from Mozambique relative to Germany. In our story, instead, Mozambique should not be penalised relative to Germany, since Ghana's mine-to-coast infrastructure
} 
Therefore, we add to the baseline specification interactions with a dummy equal to 1 if the origin country of the bilateral trade flow is from the same continent as the destination country $\left(\right.$ Continent $\left._{o d}\right)$.

The result is given in column 5 of Table 7 . We still find that coastal countries with more mines import relatively less from neighbors, and the opposite for landlocked countries: this is now relative to non African countries, and can be seen by summing the coefficients on $N_{o d} M_{d}$ and Continent ${ }_{o d} M_{d}$ for coastal, and $N_{o d} L_{d} M_{d}$ and Continent ${ }_{o d} L_{d} M_{d}$ for landlocked (these sums, $-0.544^{*}$ and $0.630^{* *}$, are reported at the bottom of the table). The coefficients on Continent $_{\text {od }} M_{d}$ and Continent ${ }_{o d} L_{d} M_{d}$ provide the marginal effect of mines on imports from non-neighbouring African countries, relative to imports from non-African countries, for coastal and landlocked country respectively. As expected, both coefficients are non-negative. In fact, the first coefficient is even positive and significant, suggesting for coastal countries a positive asymmetric effect of mine-related transport infrastructure on imports from non-neighboring African countries, relative to imports from non-neighboring non-African countries. This differential effect of mines could be due to the fact that the former group of countries will on average be closer to an African destination: the mine-to-coast infrastructure will then improve a larger proportion of the route used by traders.

Exports. We next turn to analysing exports. Multiple uses of infrastructure may mean that the mine-related transport infrastructure may be used for non-resource exports as well. If that is the case we should find that coastal countries with more mines export relatively less to neighbors. For landlocked countries, this effect should be weaker, since trade costs for exports have declined towards the neighboring (transit) markets. To test this, we replace $M_{d}, L_{d}$ and $A_{d}$ with their origin counterparts $M_{o}, L_{o}$ and $A_{o}$, so that we are now looking at exports. Furthermore, we change the dependent variable to three measures of trade: total trade, trade net of ores and metal exports, and trade net of all natural resources (incl. agricultural natural resources), or manufacturing. Results are presented in Table 8. We find a negative coefficient on relative exports to neighbors, although it is insignificant, and for landlocked countries we find a significant increase in relative exports to neighbors. The former insignificant effect could be due to the fact that the mineto-coast infrastructure connects coastal countries to countries that are strong in manufactured

should in principle benefit both in the same way. (In contrast, at least some of the imports from Ivory Coast will not benefit: those that are more cheap to carry overland even after the mine-to-coast infrastructure has been built). 
goods, such as China: import competition may then drown the positive trade cost effect. This is plausible given the effects on imports.

Robustness. Up to now we implicitly assumed that the intensive margin of trade (how much is traded) and the extensive margin of trade (whether there is trade) were independently determined. In this section we relax that assumption and allow for zero trade flows explicitly.

We start by specifying a Poisson model that treats trade as a count variable following Santos Silva and Tenreyro (2006). Column 1 shows the result of this maximum likelihood estimation and shows that our main results hold. In column 2 we use the same estimator but change the definition of $M_{d}$ to the index weighted sum of mine to port road kilometers. The result is still robust and compared to Table 6 the coefficients are more similar between the two proxies. Alternatively, we perform a Heckman 2-step sample selection estimator (Heckman, 1979) which allows for different coefficients to determine the extensive margin of trade. Column 3 is a probit regression of a dummy equal to one if trade is positive on all right hand side variables and an excluded instrument. We follow Helpman et al. (2008) and use an indicator of whether the number of procedures and days to start a business is above median in both the origin and the destination country as a measure of the fixed costs of engaging in trade. ${ }^{47}$ This variable is significant and predicts that trade is less likely. Column 4 is the second step and includes the Mills ratio to correct for any sample selection. We still find relatively less trade with neighbors for coastal mining countries and relatively more for landlocked mining countries.

Next we allow for correlated errors between all origins of the same destination (column 5) or both between all origins of the same destination and all destinations of the same origin (column 6 ) which uses the procedure of Cameron et al. (2011). The standard errors are only marginally larger than in the baseline case with heteroskedasticity robust standard errors (which in our setting is identical to clustering on each country-pair). This suggest that any remaining correlation in the errors is low, that our regressors capture almost all of the shocks, and that any heteroscedasticity does not bias the standard errors. We therefore favor robust standard errors, because multi-way clustering produces a more variable estimate of the covariance matrix and because multi-way clustering tends to over-reject the null when the number of clusters is small (Cameron and Miller, 2015).

\footnotetext{
${ }^{47}$ Data from the World Bank Development Indicators 2012. The variables are: time required to start a business (days) (IC.REG.PROC) and start-up procedures to register a business (number) (IC.REG.DURS), which come from the Doing Business project (Djankov et al., 2002).
} 
In Table 10 we show that choosing the year 2006 does not drive our results. We selected this year because it has the largest number of observations for Africa which improves efficiency. In fact, the results for coastal countries are more significant and of higher magnitude in 2004, 2005 and 2007. The landlocked marginal effect of mines is positive in all years and more significant in 2007 and 2008.

\section{Conclusions}

Coastal African countries with more mines import less from neighbors, relative to overseas countries, which confirms our first hypothesis. In contrast, landlocked African countries with more mines import relatively more from neighbors, which confirms our second hypothesis. Our tests suggest that this is due to mine-to-coast transport infrastructure, which reduces the relative cost of trading with overseas countries more than with neighbors. Our findings shed light on the link between natural resource endowments and Africa's peculiar interior-to-coast transportation networks, as well as on the trade consequences of such networks. The above-mentioned pattern can also be detected in a broader sample of recently decolonised countries, but it is not present in other countries. This last finding is consistent with (though not a proof of) the view that colonial transport networks - which are likely to have a greater influence on the shape of recently decolonised countries - were designed primarily to export natural resources, and still have an influence on the way in which former colonies trade today.

Two caveats must be made. First, our results only inform us about relative trade costs. We cannot rule out that the mine-to-coast infrastructure reduces absolute trade costs vis-a-vis both neighbors and overseas countries, thus increasing trade with both. Second, we do not know what the counterfactual to the mine-to-coast infrastructure would have been. It is plausible that, had those resource-rich countries had fewer mineral resources and thus less mine-to-coast transport infrastructure, they would have had less transport infrastructure overall, and thus perhaps higher average trade costs vis-a-vis all countries. Similarly, it is plausible that, had those countries not been colonised, they might have had less transport infrastructure overall; or, perhaps, they might have developed the exact same transport infrastructure (for example, if one believes that this infrastructure is optimal).

Still, our results have important implications for the redistributive and competitive effects of 
resource-related infrastructural investment. A mining boom in an African country may naturally be expected to generate positive spillovers on other countries by generating greater demand for their products (see, for example, Venables, 2011). However, if the boom is associated with a change in relative costs that favours overseas countries (which according to our results will be the case for coastal booming countries), fewer of these spillovers will benefit neighboring African countries than one may otherwise have expected. Another implication is that firms located in neighboring countries who do not benefit from the mine-to-coast infrastructure (for example, because they trade more cheaply through other routes), will, as a result of that infrastructure, face higher trade costs relative to their overseas competitors. This effect may also apply to domestic firms, if their location is such that they do not benefit from the mine-to-coast infrastructure directly. Firms may well exit because of excessive competition, which in turn depends on relative (and not absolute) costs. By affecting relative trade costs, the mine-to-coast infrastructure may then have a negative competitive effect on regional and domestic producers. ${ }^{48}$

These effects should be kept in mind when evaluating the impact of infrastructural investment in Africa. In this respect, it is interesting to consider the recent surge of Chinese investment in Africa, particularly in comparison with the investment strategy advocated by development agencies such as the African Development Bank (ADB). For years, the ADB has been advocating a major expansion in Africa's transport infrastructure, a large chunk of which should consist of long-distance, intra-African (interior-to-interior) connections (e.g. ADB, 2003, p. 17). On the other hand, the lion's share of recent investment has been taken up by China and its state-owned construction companies. Do these Chinese investments help achieve the expansion path advocated by the ADB? To get a sense of this, we collected data (available in the Online Appendix) on the trajectory of the 40 largest Chinese road and rail investment projects between 2000 and 2013. We found that only 5 of these 40 projects connected two African countries with each other, and in 4 out of 5 cases this involved the connection of a landlocked country to the coast. Furthermore, $83 \%$ (by value) of the projects have an interior-to-coast shape, in the sense that they are primarily designed to connect the interior of a country to the coast. To a first (and admittedly superficial) look the Chinese investments seem more oriented towards reinforcing Africa's interior-to-coast transport network then to achieve the more balanced expansion path advocated by the ADB.

\footnotetext{
${ }^{48}$ In a similar vein, Venables (2003) showed that the interests of a middle-income country may best be served by reducing trade costs vis-a-vis a neighboring low-income country, rather than decreasing them vis-a-vis an overseas developed country.
} 
While one cannot underestimate the importance of the Chinese roads and railways for the African countries, results in this paper suggest that their potential redistributive and competitive effects should also be taken into account.

Ideally, the debate on Africa's infrastructural development should be based on an answer to the following question: would Africa be better off by improving its internal connectivity, and thus favour the expansion of its regional trade, or would it be better off by improving its interiorto-coast connections, and thus favour its trade with the wider world? Unfortunately, there is no easy answer to this question. For example, suppose we took the view that Africa has the largest trade opportunities with the wider world because of a comparative advantage in natural resources, but that some of its manufacturing industries are also quite competitive in local and regional trade. From a static comparative advantage perspective, it would make a lot of sense to expand the interior-to-coast connections that support Africa's main trade. However, such an investment may well backfire from a dynamic perspective, since it may lead to Africa specialising away from manufacturing, which is where sustained economic growth is typically generated (e.g., Grossman and Helpmann, 1991). This example suggests that an answer to this question can only be given in the context of a properly estimated model of infrastructural investment, trade and growth. We think this is a challenging but fascinating avenue for future research.

\section{References}

[1] African Development Bank (2003). Review of the Implementation Status of the Trans African Highways and the Missing Links - Volume 1: Main Report, available at www.afdb.org.

[2] Amin, S. (1972). "Underdevelopment and Development in Black Africa - Origins and Contemporary Forms", in the Journal of Modern African Studies, Vol. 10, No. 4, pp. 503-524.

[3] Banerjee, A., E. Duflo, and N. Qian (2012). "On the Road: Access to Transportation Infrastructure and Economic Growth in China", NBER Working Papers, N. 17897.

[4] Buys, P., U. Deichmann and D. Wheeler (2010). "Road Network Upgrading and Overland Trade Expansion in Sub-Saharan Africa", in Journal of African Economies, Vol. 19, No. 3, pp. 399-342. 
[5] Cameron, A. C., J. B. Gelbach, and D. L. Miller (2011). "Robust inference with multi-way clustering", Journal of Business and Economic Statistics, Vol. 29, No. 2, pp. 238-249.

[6] Cameron, A. C. and D. L. Miller (2015). "A Practitioner's Guide to Cluster-Robust Inference", Journal of Human Resources Vol. 50, No. 2, pp. 317-373.

[7] Collier, P. and A. J. Venables (2010). "Trade and Economic Performance: Does Africas Fragmentation Matter?", in Lin, J. Y., and B. Pleskovic (Eds.), People, Politics and Globalization, World Bank, 2009 ABCDE Conference.

[8] Cosar, A. K. and B. Demir (2015). "Domestic Road Infrastructure and International Trade: Evidence from Turkey", Journal of Development Economics, Vol. 118, pp. 232-244.

[9] Djankov, S., R. La Porta, F. Lopez-de-Silanes, and A. Shleifer (2002). "The Regulation of Entry", Quarterly Journal of Economics, Vol. 117, pp. 1-37.

[10] Donaldson, D. (forthcoming). "Railroads of the Raj: Estimating the Impact of Transportation Infrastructure", forthcoming, American Economic Review.

[11] Dos Santos, T. (1970). "The Structure of Dependence", American Economic Review Vol. 60, No. 2, pp. 231-236.

[12] Duranton, G., P. M. Morrow and M. A. Turner (2014). "Roads and Trade: Evidence from the US", Review of Economic Studies, Vol. 81, No. 2, pp. 681-724.

[13] Easterly, W. and R. Levine (1998). "Troubles with Neighbors: Africa's Problem, Africa's Opportunity", in the Journal of African Economies Vol. 7, No. 1, pp. 120-142.

[14] Egger, Peter H. and M. Larch (2008). "Interdependent Preferential Trade Agreement Memberships: An Empirical Analysis", in Journal of International Economics Vol. 76, No. 2, pp. 384-399.

[15] Faber, B. (2014). "Trade Integration, Market Size, and Industrialization: Evidence from China's National Trunk Highway System", in Review of Economic Studies, Vol. 81, No. 3, pp. 1046-1070.

[16] Freund, B. (1998). The Making of Contemporary Africa the Development of African Society Since 1800, Basingstoke (UK), MacMillan Press. 
[17] Grossman, G. and H. Helpmann (1991). Innovation and Growth in the Global Economy, MIT Press.

[18] Halbouty, M. T., A. Meyerhoff, R. E. King, R. H. Dott, D. Klemme and T. Shabad, (1970). "World's Giant Oil and Gas Fields, Geologic Factors Affecting Their Formation, and Basin Classification: Part I: Giant Oil and Gas Fields." in AAPG Memoir 14: Geology of Giant Petroleum Fields, pp. 502-528.

[19] Head, K. and T. Mayer (2014). "Gravity Equations: Workhorse, Toolkit, and Cookbook" in Gopinath, G. et al. (Eds), Handbook of International Economics Vol. 4, North Holland.

[20] Head, K., T. Mayer and J. Ries (2010). "The erosion of colonial trade linkages after independence", Journal of International Economics, Vol. 81, No. 1, pp. 1-14.

[21] Heckman, James J. (1979). "Sample Selection Bias as a Specification Error", in Econometrica, Vol. 47, No. 1, pp. 153-161.

[22] Helpman, E., M. Melitz and Y. Rubinstein (2008). "Estimating trade flows: trading partners and trade volumes", in Quarterly Journal of Economics, Vol. 123, No. 2, pp. 441-487.

[23] Horn, M. K. (2003) "Giant Fields 1868-2003 (CD-ROM)", in Halbouty, M. K. (Ed.), Giant Oil and Gas Fields of the Decade, 1990-1999, Housto, AAPG Memoir 78.

[24] Huillery, E. (2009). "History Matters: The Long-Term Impact of Colonial Public Investments in French West Africa", American Economic Journal: Applied Economics, Vol. 1, No. 2, pp. $176-221$.

[25] Iyer, L. (2010). "Direct versus Indirect Colonial Rule in India: Long-term Consequences", The Review of Economics and Statistics, Vol. 92, No. 4, pp. 693-713.

[26] Jedwab, R. and A. Moradi (forthcoming). "The Permanent Effects of Transportation Revolutions in Poor Countries: Evidence from Africa", forthcoming, Review of Economics and Statistics.

[27] Keller, W. and C. H. Shiue (2008). "Institutions, Technology, and Trade", NBER Working Papers, N. 13913. 
[28] Limao, N. and A. J. Venables (2001). "Infrastructure, Geographical Disadvantage, Transport Costs, and Trade", in The World Bank Economic Review, Vol. 15, No. 3, pp. 451-479.

[29] Linder, S. (1961). An Essay on Trade and Transformation, Stockholm, Almqvist \& Wiksell.

[30] Michaels, G. (2008). "The Effect of Trade on the Demand for Skill: Evidence from the Interstate Highway System", Review of Economics and Statistics, Vol. 90, No. 4, pp. 683701.

[31] Nunn N. (2008). "The long-term effects of Africas slave trades", Quarterly Journal of Econonics, Vol. 123, No. 1, pp. 139-176.

[32] van der Ploeg, F. (2011). "Natural Resources: Curse of Blessing?" in Journal of Economic Literature Vol. 49, No. 2, pp. 366-420.

[33] Roberts, M. and U. Deichmann (2011). "International Growth Spillovers, Geography and Infrastructure", in the World Economy, Vol. 34, No. 9. pp. 1507-1533.

[34] Rodney, W. (1982). How Europe Underdeveloped Africa, Washington DC, Howard University Press.

[35] Sachs, J. D., J. W. McArthur, G. Schmidt-Traub, M. Kruk, C. Bahadur, M. Faye and G. McCord (2004). "Ending Africas Poverty Trap", in Brookings Papers on Economic Activity No. 1 (2004), pp. 117-226.

[36] Santos Silva, J. M. C. and Silvana Tenreyro (2006). "The Log of Gravity", Review of Economics and Statistics, Vol. 88, No. 4, pp. 641-658.

[37] Venables, A. J. (2003). "Winners and Losers from Regional Integration Agreements", in the Economic Journal Vol. 113, pp. 747-761.

[38] Venables, A. J. (2011). "Economic Integration in Remote Resource-Rich Regions", in R. Barro and J. W. Lee (Eds.), Costs and benefits of economic integration in Asia, Oxford University Press.

[39] World Bank (2010) Africa's Infrastructure: A Time for Transformation, Washington DC, World Bank. 
Figures and Tables 


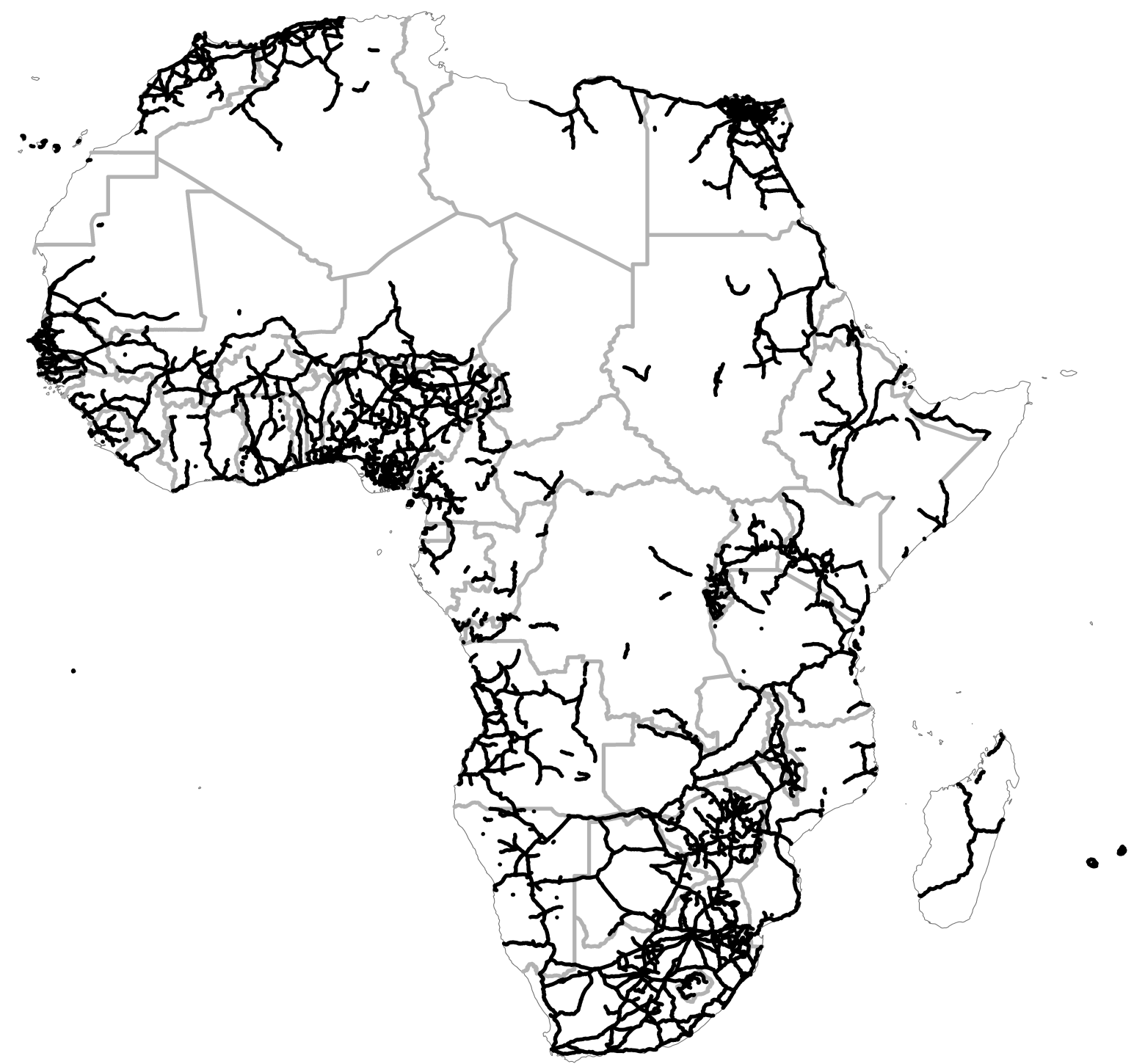

Figure 1: African main and asphalt roads, 2002. Source: 'Vmap0' from (www.mapability.com) and African Development Bank (www.infrastructureafrica.org), prepared for World Bank (2010). 


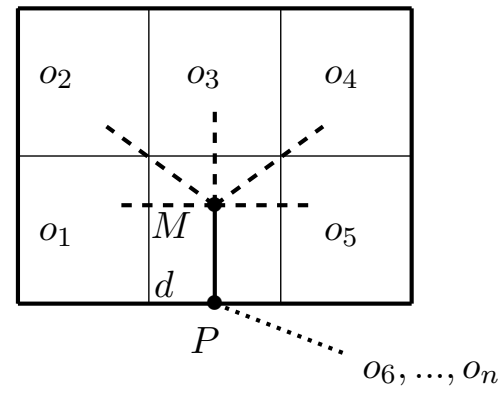

Panel I: coastal $d$

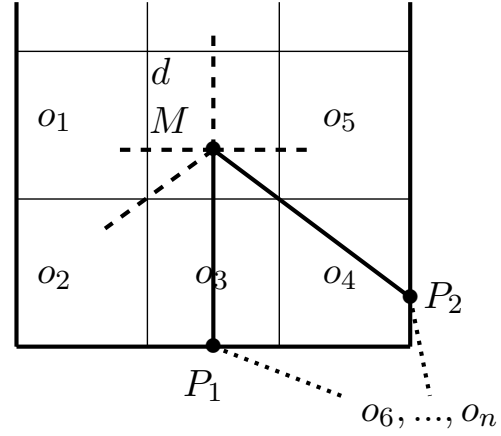

Panel II: landlocked $d$

Figure 2: Mine-related transport infrastructure, coastal and landlocked destination.

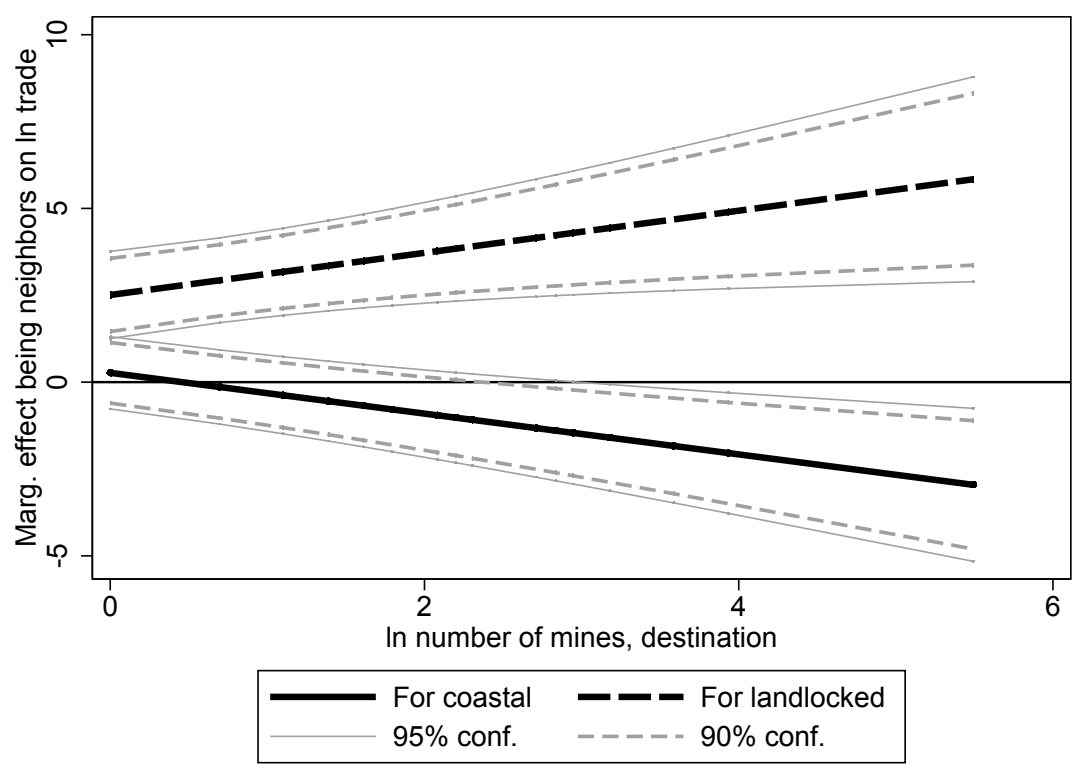

Figure 3: Marginal effect of $N_{o d}$ on imports for $A_{d}=0$ by landlocked status, Africa sample. 

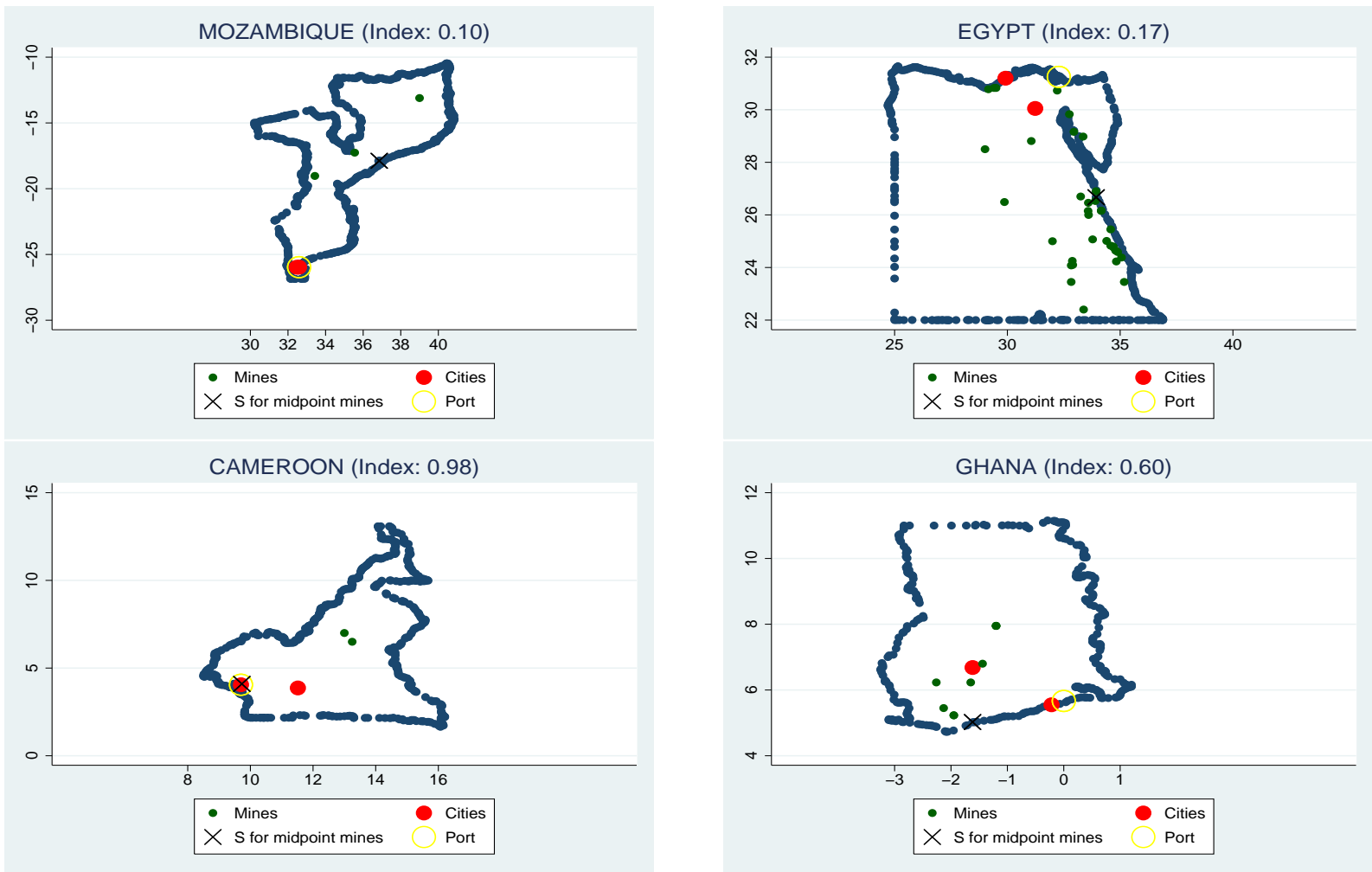

Figure 4: Average mine impact index for four African countries. 
Table 1: Average imports by region

\begin{tabular}{|c|c|c|c|c|}
\hline Country mean of: & $\begin{array}{l}\text { Imports } \\
\text { (USD mln) }\end{array}$ & $\begin{array}{l}\% \text { imports } \\
\text { from neigh- } \\
\text { bors }\end{array}$ & $\begin{array}{l}\text { Imports } \\
\text { (USD mln) }\end{array}$ & $\begin{array}{l}\% \text { imports } \\
\text { from neigh- } \\
\text { bors }\end{array}$ \\
\hline Region & \multicolumn{2}{|c|}{ Not landlocked } & \multicolumn{2}{|c|}{ Landlocked } \\
\hline non-former colonies & 4,413 & 23.21 & 927 & 44.93 \\
\hline former colonies & 597 & 14.42 & 277 & 30.17 \\
\hline Africa & 540 & 10.43 & 203 & 25.71 \\
\hline
\end{tabular}

Note: the table shows country means by region and landlocked status for ln imports, and for the percentage of total imports originating in neighboring countries.

Table 2: Average trade patterns, Africa versus Rest of the World

\begin{tabular}{lccccccc}
\hline \multirow{2}{*}{$\begin{array}{l}\text { Country mean of: } \\
\text { Region }\end{array}$} & \multicolumn{2}{c}{ Share of manufactures in imports from } & & \multicolumn{3}{c}{ Share of manufactures in exports to } \\
\cline { 2 - 3 } & All & Neighbors & Non-neighbors & & All & Neighbors & Non-neighbors \\
\hline Africa & 0.73 & 0.56 & 0.74 & & 0.36 & 0.48 & 0.35 \\
Rest of the World & 0.74 & 0.67 & 0.77 & & 0.61 & 0.60 & 0.64 \\
\hline
\end{tabular}

Note: the table shows country means by region for the share of manufactures in the average bilateral trade flow, average bilateral trade flow with neighbors, and average bilateral trade flow with non-neighbors. Manufactures are defined as all trade minus SITC divisions $0,1,2,3,4$ and 68.

Table 3: Average mines by region

\begin{tabular}{lccccc}
\hline Country mean of: & \multicolumn{2}{c}{$m_{d} m_{d} / a_{d}$} & & \multicolumn{2}{c}{$m_{d} m_{d} / a_{d}$} \\
\cline { 2 - 3 } \cline { 5 - 6 } Region & \multicolumn{2}{c}{ Not landlocked } & & \multicolumn{2}{c}{ Landlocked } \\
\hline non-former colonies & 376.41 & 1.99 & & 15.02 & 0.27 \\
former colonies & 17.95 & 13.48 & & 5.91 & 0.29 \\
Africa & 10.56 & 0.15 & & 5.67 & 0.23 \\
\hline
\end{tabular}

Note: $m_{d}$ and $a_{d}$ equal, respectively, the number of mines in each country, and country area expressed in $10^{4}$ sq. $\mathrm{km}$. The table shows country means by region and landlocked status for the number of mines, and the number of mines per $10^{4} \mathrm{sq}$. $\mathrm{km}$. The mean of $m_{d} / a_{d}$ is large for coastal former colonies because of Nauru and other island states. The number of mines in coastal non-former colonies is large due to the large number of mines in the United States. Without the United States this value for $m_{d}$ is 93.74 and $m_{d} / a_{d}=1.73$. 
Table 4: Summary statistics, Africa sample

\begin{tabular}{|c|c|c|c|c|c|c|}
\hline Variable & $\mathrm{N}$ & mean & median & sd & $\min$ & $\max$ \\
\hline ln bilateral trade & 6,026 & 13.08 & 13.29 & 3.86 & 0.69 & 22.87 \\
\hline$N_{o d}$ & 6,026 & 0.03 & 0.00 & 0.17 & 0.00 & 1.00 \\
\hline$M_{d}: \ln$ № mines +1 , destination & 6,026 & 1.35 & 1.39 & 1.29 & 0.00 & 5.49 \\
\hline$A_{d}$ & 6,026 & 1.50 & 2.04 & 2.01 & -4.72 & 3.90 \\
\hline$L_{d}$ & 6,026 & 0.27 & 0.00 & 0.44 & 0.00 & 1.00 \\
\hline Linder & 6,026 & 0.37 & 0.64 & 1.11 & -7.95 & 1.85 \\
\hline$N_{o d} *$ Shared empire, one colonizer & 6,026 & 0.02 & 0.00 & 0.12 & 0.00 & 1.00 \\
\hline$N_{o d} *$ Shared empire, none colonizer & 6,026 & 0.00 & 0.00 & 0.03 & 0.00 & 1.00 \\
\hline Ln distance & 6,026 & 8.57 & 8.67 & 0.70 & 4.88 & 9.87 \\
\hline Shared language & 6,026 & 0.25 & 0.00 & 0.43 & 0.00 & 1.00 \\
\hline Shared legal origin & 6,026 & 0.41 & 0.00 & 0.49 & 0.00 & 1.00 \\
\hline ColHist & 6,026 & 0.01 & 0.00 & 0.10 & 0.00 & 1.00 \\
\hline RTA & 6,026 & 0.08 & 0.00 & 0.28 & 0.00 & 1.00 \\
\hline Both WTO & 6,026 & 0.68 & 1.00 & 0.47 & 0.00 & 1.00 \\
\hline Shared currency & 6,026 & 0.02 & 0.00 & 0.15 & 0.00 & 1.00 \\
\hline $\mathrm{ACP}$ & 6,026 & 0.00 & 0.00 & 0.00 & 0.00 & 0.00 \\
\hline ln № Mines per $10^{6}$ square $\mathrm{km}$ & 4,219 & 2.50 & 2.61 & 1.34 & -0.23 & 5.29 \\
\hline № Mines per $10^{6}$ square $\mathrm{km}$ & 6,026 & 19.96 & 3.74 & 38.42 & 0 & 197.56 \\
\hline № Mines & 6,026 & 12.62 & 3 & 41.53 & 0 & 241 \\
\hline $\ln \left(\sum_{j} M_{j} P+1\right)$ & 6,026 & 5.48 & 7.32 & 4.02 & 0.00 & 12.07 \\
\hline $\ln \left(\sum_{j} \min \left(M_{j} S_{j}, M_{j} P\right)+1\right)$ & 6,026 & 5.03 & 6.58 & 3.87 & 0.00 & 11.80 \\
\hline $\ln \left(\sum_{j} I_{j} M_{j} P+1\right)$ & 6,026 & 5.22 & 6.50 & 3.66 & 0.00 & 11.66 \\
\hline $\ln \left(\sum_{j} I_{j}^{t i m e} M_{j} P^{\text {time }}+1\right)$ & 6,026 & 8.05 & 10.64 & 5.41 & 0.00 & 15.46 \\
\hline ln oil \& gas fields & 6,026 & 0.47 & 0.00 & 0.93 & 0.00 & 3.40 \\
\hline ln deposits & 45 & 3.13 & 3.14 & 1.07 & 0.69 & 6.23 \\
\hline ln total exports & 5,808 & 12.36 & 12.28 & 3.96 & 0.69 & 24.09 \\
\hline ln non ores \& metals exports & 5,756 & 12.26 & 12.18 & 3.93 & 0.00 & 24.09 \\
\hline ln non-resource exports & 5,077 & 11.36 & 11.21 & 3.74 & 0.00 & 22.77 \\
\hline Procedures and days above median & 9,833 & 0.35 & 0.00 & 0.48 & 0.00 & 1.00 \\
\hline
\end{tabular}

$\boldsymbol{N}_{\boldsymbol{o d}}=$ neighbor dummy; $\boldsymbol{A}_{\boldsymbol{d}}=\ln$ land area, deviation from world average; $\boldsymbol{L}_{\boldsymbol{d}}=$ landlocked destination dummy; $\boldsymbol{M}_{\boldsymbol{j}} \boldsymbol{P}=$ distance along roads from mine $\boldsymbol{j}$ to port in kilometer; $\boldsymbol{M}_{\boldsymbol{j}} \boldsymbol{S}_{\boldsymbol{j}}=$ distance along roads from mine $\boldsymbol{j}$ to coast; $\boldsymbol{M}_{\boldsymbol{j}} \boldsymbol{P}^{\text {time }}=$ distance along roads from mine $\boldsymbol{j}$ to port in travel time; $\boldsymbol{I}_{\boldsymbol{j}}=$ mine $\boldsymbol{j}$ impact index based on distance; $\boldsymbol{I}_{j}^{\text {time }}=$ mine $\boldsymbol{j}$ impact index based on travel time. 
Table 5: Local mining and relative trade with neighbors: baseline

\begin{tabular}{|c|c|c|c|}
\hline \multirow[b]{3}{*}{ Sample, destination equals: } & \multicolumn{3}{|c|}{$\ln ($ bilateral trade $)$} \\
\hline & {$[1]$} & {$[2]$} & {$[3]$} \\
\hline & Africa & former colonies & non-former colonies \\
\hline \multirow{2}{*}{$N_{o d}$} & 0.269 & 0.143 & $0.507^{*}$ \\
\hline & $(0.648)$ & $(0.400)$ & $(0.287)$ \\
\hline \multirow{2}{*}{$N_{o d} M_{d}$} & $-0.587^{*}$ & $-0.431^{* *}$ & -0.028 \\
\hline & $(0.314)$ & $(0.191)$ & $(0.104)$ \\
\hline \multirow[t]{2}{*}{$N_{o d} L_{d}$} & $2.240^{* * *}$ & $1.094^{* *}$ & -0.434 \\
\hline & $(0.831)$ & $(0.504)$ & $(0.398)$ \\
\hline \multirow[t]{2}{*}{$N_{o d} L_{d} M_{d}$} & $1.193^{* * *}$ & $0.715^{* *}$ & -0.175 \\
\hline & $(0.397)$ & $(0.301)$ & $(0.196)$ \\
\hline \multirow[t]{2}{*}{ Linder } & $-0.083^{* *}$ & $-0.089 * * *$ & $0.069^{* * *}$ \\
\hline & $(0.039)$ & $(0.019)$ & $(0.024)$ \\
\hline \multirow[t]{2}{*}{$N_{o d} A_{d}$} & $0.592^{* * *}$ & $0.389 * * *$ & -0.041 \\
\hline & $(0.215)$ & $(0.133)$ & $(0.120)$ \\
\hline \multirow[t]{2}{*}{$N_{o d} L_{d} A_{d}$} & $-0.718^{* *}$ & -0.113 & $0.880^{* * *}$ \\
\hline & $(0.308)$ & $(0.195)$ & $(0.291)$ \\
\hline \multirow[t]{2}{*}{$N_{o d} *$ Shared empire, none colonizer } & $-0.671^{*}$ & 0.041 & $1.262^{* * *}$ \\
\hline & $(0.405)$ & $(0.291)$ & $(0.383)$ \\
\hline \multirow{2}{*}{$N_{o d} *$ Shared empire, one colonizer } & -0.695 & -0.389 & $-1.249 * * *$ \\
\hline & $(0.945)$ & $(0.695)$ & $(0.369)$ \\
\hline \multirow[t]{2}{*}{ ln distance } & $-1.785^{* * *}$ & $-1.682^{* * *}$ & $-1.333^{* * *}$ \\
\hline & $(0.089)$ & $(0.035)$ & $(0.046)$ \\
\hline \multirow[t]{2}{*}{ Shared language } & $0.781^{* * *}$ & $0.801^{* * *}$ & $0.538 * * *$ \\
\hline & $(0.099)$ & $(0.066)$ & $(0.110)$ \\
\hline \multirow[t]{2}{*}{ Shared legal origin } & $0.136^{*}$ & $0.225^{* * *}$ & $0.578^{* * *}$ \\
\hline & $(0.080)$ & $(0.046)$ & $(0.059)$ \\
\hline \multirow[t]{2}{*}{ ColHist } & $1.349^{* * *}$ & $1.081^{* * *}$ & $0.895^{* * *}$ \\
\hline & $(0.244)$ & $(0.155)$ & $(0.150)$ \\
\hline \multirow[t]{2}{*}{ RTA } & $0.366^{* * *}$ & $0.650 * * *$ & $0.492^{* * *}$ \\
\hline & $(0.142)$ & $(0.082)$ & $(0.084)$ \\
\hline \multirow[t]{2}{*}{ Both WTO } & -0.254 & $0.401^{* *}$ & 0.118 \\
\hline & $(0.242)$ & $(0.156)$ & $(0.202)$ \\
\hline \multirow[t]{2}{*}{ Shared currency } & $1.139 * * *$ & $0.966^{* * *}$ & $-0.718^{* * *}$ \\
\hline & $(0.273)$ & $(0.199)$ & $(0.144)$ \\
\hline \multirow[t]{2}{*}{$\mathrm{ACP}$} & - & -0.238 & $0.827 * * *$ \\
\hline & & $(0.240)$ & $(0.114)$ \\
\hline Destination and origin FE & yes & yes & yes \\
\hline Observations & 6,026 & 14,911 & 9,134 \\
\hline R-squared & 0.685 & 0.704 & 0.782 \\
\hline \multicolumn{4}{|c|}{ Marginal effect of $M_{d}$ on $\ln$ imports from neighbors for $A_{d}=0$} \\
\hline If $L_{d}=0$ & $-0.587^{*}$ & $-0.431^{* *}$ & -0.028 \\
\hline If $L_{d}=1$ & $0.606^{* *}$ & 0.284 & -0.204 \\
\hline
\end{tabular}

Note: This table shows OLS regressions to estimate the impact of mining in both landlocked and coastal destination countries on relative trade with neighboring countries. Variables 2-4 and 6-9 are interactions: $\boldsymbol{N}_{\text {od }}=$ neighbor dummy; $\boldsymbol{M}_{\boldsymbol{d}}=$ mines in the destination country (in $\left.\ln +1\right) ; \boldsymbol{A}_{\boldsymbol{d}}=\ln$ land area, deviation from world average; $\boldsymbol{L}_{\boldsymbol{d}}$ $=$ landlocked destination dummy; Linder $=$ absolute difference in per capita GDP; ColHist $=1$ for pair ever in colonial relationship. Origin and destination fixed effects are included. Robust standard errors in parentheses: $* * *$ $\mathrm{p}<0.01,{ }^{* *} \mathrm{p}<0.05,{ }^{*} \mathrm{p}<0.1$. The non-former colonieg.9former colonies and Africa samples refer to all bilateral trade flows in which the destinations country is: not a former colony; a former colony; in Africa, respectively. 


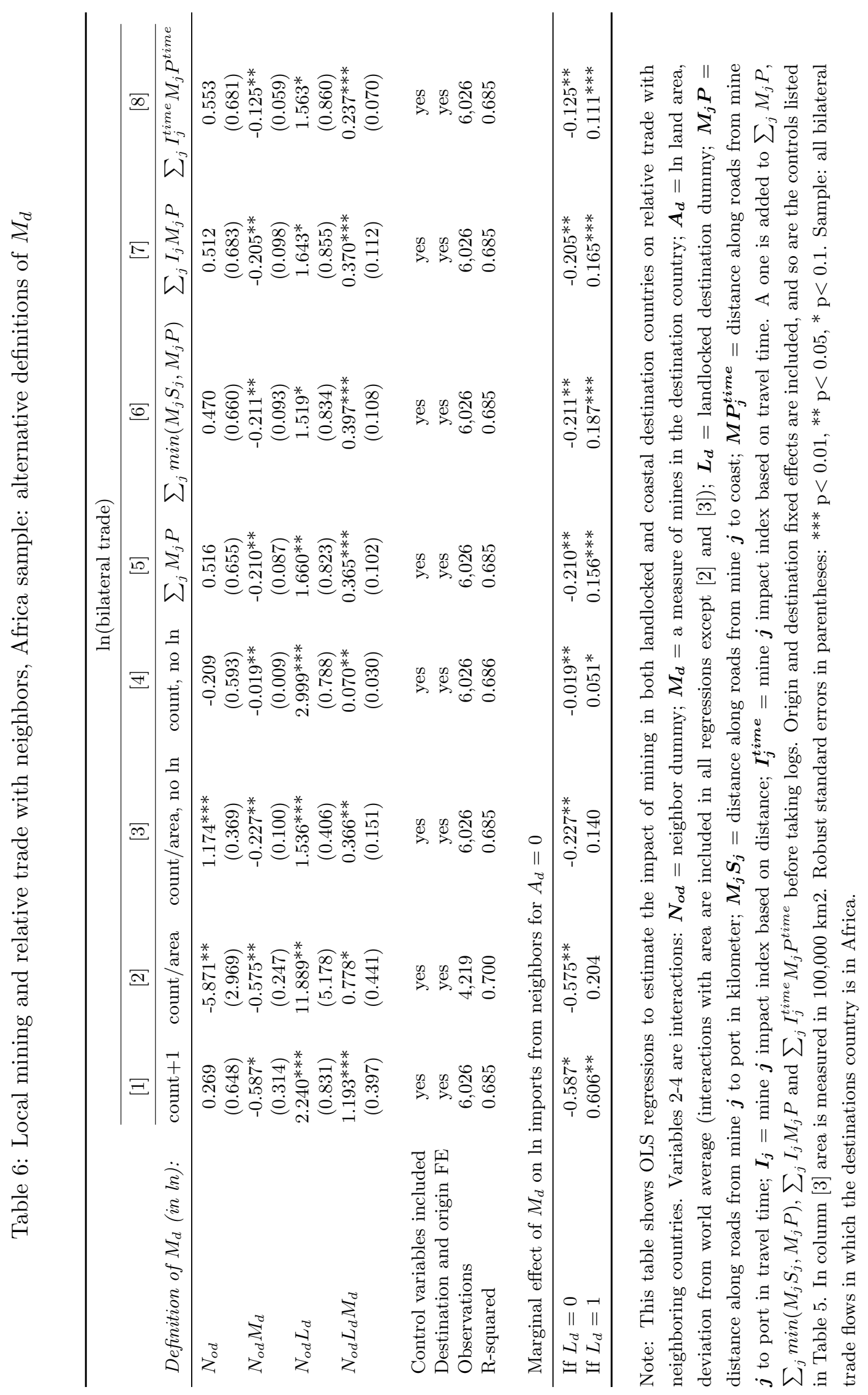


Table 7: Local mining and relative trade with neighbors, Africa sample: transit neighbors, placebo test, IV and same-continent interactions

\begin{tabular}{|c|c|c|c|c|c|}
\hline \multirow[t]{2}{*}{ Dependent variable: } & \multicolumn{5}{|c|}{$\log ($ bilateral trade $)$} \\
\hline & $\begin{array}{c}{[1]} \\
\text { Baseline }\end{array}$ & $\begin{array}{c}{[2]} \\
\text { transit }\end{array}$ & $\begin{array}{c}{[3]} \\
\text { oil\&gas }\end{array}$ & $\begin{array}{c}{[4]} \\
\text { IV deposits }\end{array}$ & $\begin{array}{c}{[5]} \\
\text { same continent }\end{array}$ \\
\hline$N_{o d}$ & $\begin{array}{c}0.269 \\
(0.648)\end{array}$ & $\begin{array}{c}1.256^{* *} \\
(0.557)\end{array}$ & $\begin{array}{c}0.318 \\
(0.651)\end{array}$ & $\begin{array}{c}0.764 \\
(0.817)\end{array}$ & $\begin{array}{c}0.307 \\
(0.651)\end{array}$ \\
\hline$N_{o d} M_{d}$ & $\begin{array}{c}-0.587^{*} \\
(0.314)\end{array}$ & $\begin{array}{c}-0.466^{*} \\
(0.268)\end{array}$ & $\begin{array}{c}-0.673^{* *} \\
(0.332)\end{array}$ & $\begin{array}{c}-0.975^{* *} \\
(0.403)\end{array}$ & $\begin{array}{c}-0.706^{* *} \\
(0.319)\end{array}$ \\
\hline$N_{o d} L_{d}$ & $\begin{array}{c}2.240^{* * *} \\
(0.831)\end{array}$ & & $\begin{array}{c}2.205^{* * *} \\
(0.834)\end{array}$ & $\begin{array}{c}2.068^{* *} \\
(0.964)\end{array}$ & $\begin{array}{c}2.277^{* * *} * \\
(0.835)\end{array}$ \\
\hline$N_{o d} L_{d} M_{d}$ & $\begin{array}{c}1.193^{* * *} \\
(0.397)\end{array}$ & & $\begin{array}{c}1.281^{* * *} \\
(0.411)\end{array}$ & $\begin{array}{l}1.255^{* *} \\
(0.527)\end{array}$ & $\begin{array}{c}1.248^{* * *} \\
(0.411)\end{array}$ \\
\hline$N_{o d} T L_{d}$ & & $\begin{array}{c}1.197 \\
(1.149)\end{array}$ & & & \\
\hline$N_{o d} T L_{d} M_{d}$ & & $\begin{array}{c}1.018^{* * *} \\
(0.336)\end{array}$ & & & \\
\hline$N_{o d} O G_{d}$ & & & $\begin{array}{l}-0.283 \\
(0.255)\end{array}$ & & \\
\hline Same continent dummy (Continent od $_{\text {) }}$ & & & & & $\begin{array}{l}1.298^{*} \\
(0.733)\end{array}$ \\
\hline Continent $_{o d} M_{d}$ & & & & & $\begin{array}{c}0.162^{* *} \\
(0.070)\end{array}$ \\
\hline Continent $_{\text {od }} L_{d} M_{d}$ & & & & & $\begin{array}{l}-0.073 \\
(0.139)\end{array}$ \\
\hline Control variables included & yes & yes & yes & yes & yes \\
\hline Destination and origin FE & yes & yes & yes & yes & yes \\
\hline Observations & 6,026 & 6,026 & 6,026 & 5,365 & 6,026 \\
\hline R-squared & 0.685 & 0.684 & 0.685 & 0.697 & 0.686 \\
\hline Kleibergen-Paap F-test & & & & 72.888 & \\
\hline \multicolumn{6}{|c|}{ Marginal effect of $M_{d}$ on ln imports from neighbors for $A_{d}=0$} \\
\hline If $L_{d}=0$ & $-0.587^{*}$ & & $-0.673^{* *}$ & $-0.975^{* *}$ & \\
\hline If $L_{d}=1$ & $0.606^{* *}$ & & $0.608^{* *}$ & 0.280 & \\
\hline If $T L_{d}=0$ & & $-0.466^{*}$ & & & \\
\hline If $T L_{d}=1$ & & $0.551^{* *}$ & & & \\
\hline If Continent $_{o d}=0 \& L_{d}=0$ & & & & & $-0.706^{* *}$ \\
\hline If Continent od $=1 \& L_{d}=0$ & & & & & $-0.544^{*}$ \\
\hline If Continent $_{o d}=0 \& L_{d}=1$ & & & & & $0.541^{*}$ \\
\hline If Continent $_{o d}=1 \& L_{d}=1$ & & & & & $0.630^{* *}$ \\
\hline
\end{tabular}

Note: This table shows OLS regressions to estimate the impact of mining in both landlocked and coastal destination countries on relative trade with neighboring countries. All except $N_{o d}$ and control variables are interactions: $\boldsymbol{N}_{\boldsymbol{o d}}$ = neighbor dummy; $\boldsymbol{M}_{\boldsymbol{d}}=$ a measure of mines in the destination country (in $\left.\ln +1\right) ; \boldsymbol{A}_{\boldsymbol{d}}=\ln$ land area, deviation from world average; $\boldsymbol{L}_{\boldsymbol{d}}=$ landlocked destination dummy; $\boldsymbol{T} \boldsymbol{L}_{\boldsymbol{d}}=1$ if landlocked destination imports from its transit origin. Origin and destination fixed effects are included, and so are the controls listed in Table 5. Robust standard errors in parentheses: $* * * \mathrm{p}<0.01,{ }^{* *} \mathrm{p}<0.05,{ }^{*} \mathrm{p}<0.1$. Sample: all bilateral trade flows in which the destinations country is in Africa. First stage of [4] is a cross-country regression of $M_{d}$ on (with coefficient between brackets and standard errors between square brackets) the log of the number of deposits $\left(0.856^{* * *}[0.100]\right.$, landlocked status (-0.403 [0.253]), and log GDP per capita (0.228*** [0.081]), using 45 observations and giving an R2 of 0.646 . 
Table 8: Local mining and relative trade with neighbors, Africa sample: exports

\begin{tabular}{|c|c|c|c|}
\hline \multirow[t]{2}{*}{ Dependent variable equals (log of) } & Total exports & Non ores and metal exports & Manufacturing exports \\
\hline & {$[1]$} & {$[2]$} & {$[3]$} \\
\hline \multirow[t]{2}{*}{$N_{o d}$} & $1.168^{*}$ & $1.217^{*}$ & 1.044 \\
\hline & $(0.665)$ & $(0.676)$ & $(0.759)$ \\
\hline \multirow[t]{2}{*}{$N_{o d} M_{o}$} & -0.194 & -0.174 & -0.067 \\
\hline & $(0.178)$ & $(0.179)$ & $(0.202)$ \\
\hline \multirow{2}{*}{$N_{o d} L_{o}$} & $-2.116^{* * *}$ & $-2.280 * * *$ & $-1.544^{* *}$ \\
\hline & $(0.674)$ & $(0.685)$ & $(0.755)$ \\
\hline \multirow{2}{*}{$N_{o d} L_{o} M_{o}$} & $1.387^{* * *}$ & $1.453^{* * *}$ & $1.100 * * *$ \\
\hline & $(0.336)$ & $(0.333)$ & $(0.362)$ \\
\hline Destination and origin FE & yes & yes & yes \\
\hline Observations & 5,808 & 5,756 & 5,077 \\
\hline R-squared & 0.610 & 0.608 & 0.600 \\
\hline \multicolumn{4}{|c|}{ Marginal effect of $M_{o}$ on $\ln$ imports from neighbors for $A_{o}=0$} \\
\hline If $L_{o}=0$ & -0.194 & -0.174 & -0.067 \\
\hline If $L_{o}=1$ & $1.193^{* * *}$ & $1.279^{* * *}$ & $1.033^{* * *}$ \\
\hline
\end{tabular}

Note: This table shows OLS regressions to estimate the impact of mining in both landlocked and coastal destination countries on relative trade with neighboring countries. Variables 2-4 are interactions: $\boldsymbol{N}_{\boldsymbol{o d}}=$ neighbor dummy; $\boldsymbol{M}_{\boldsymbol{o}}=$ a measure of mines in the origin country; $\boldsymbol{A}_{\boldsymbol{o}}=\ln$ land area, deviation from world average; $\boldsymbol{L}_{\boldsymbol{o}}=$ landlocked origin dummy. Origin and destination fixed effects are included, and so are the controls listed in Table 5 . Robust standard errors in parentheses: ${ }^{* * *} \mathrm{p}<0.01,{ }^{* *} \mathrm{p}<0.05,{ }^{*} \mathrm{p}<0.1,+\mathrm{p}=0.106$. Sample: all bilateral trade flows in which the origin country is in Africa. "Non ores and metals exports" equals total exports minus SITC divisions 27, 28, and 68. "Manufacturing exports" equals total exports minus SITC divisions 0, 1, 2, 3, 4 and 68. 


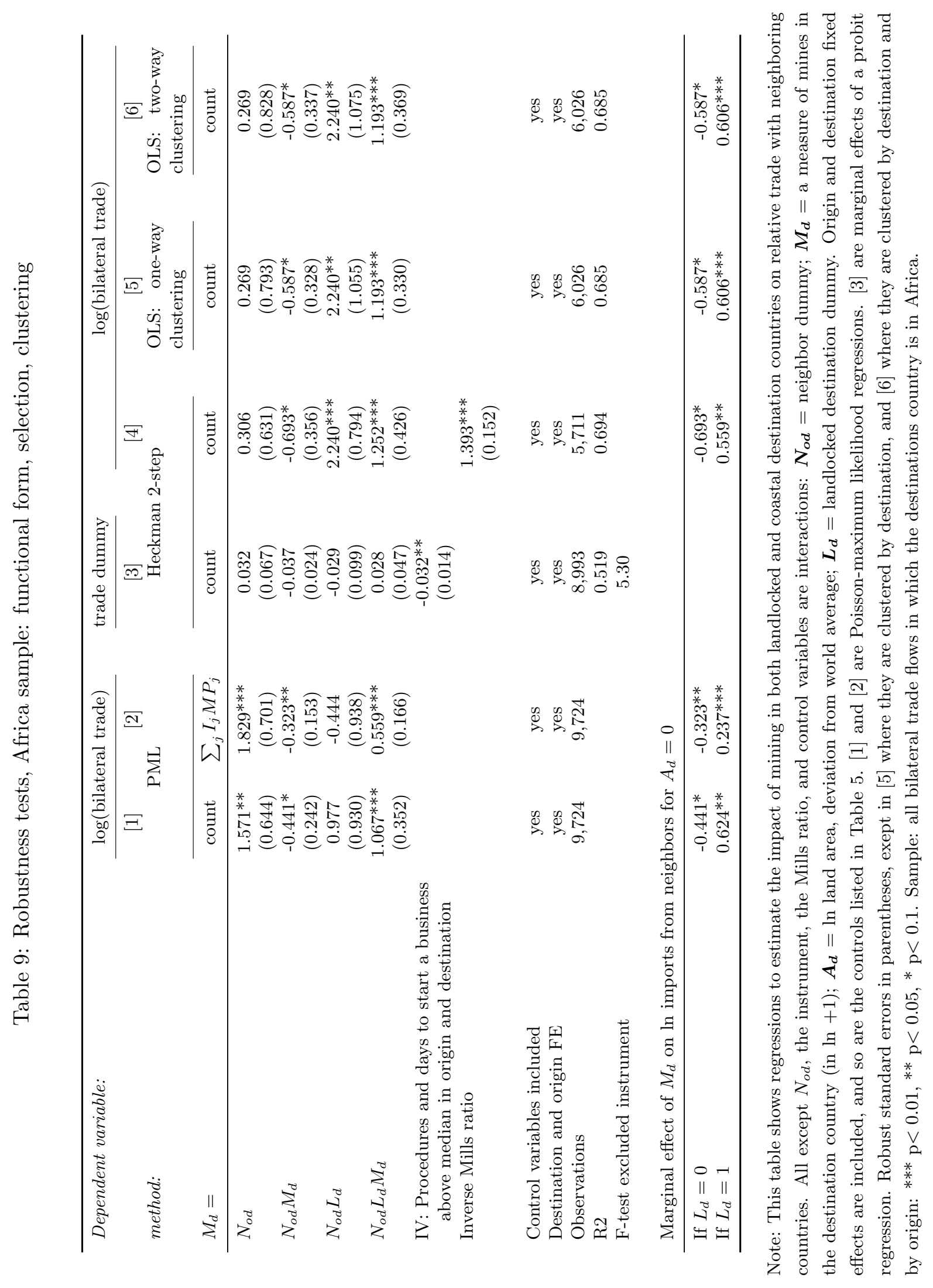


Table 10: Robustness tests, Africa sample: different years

\begin{tabular}{|c|c|c|c|c|c|}
\hline \multirow{2}{*}{$\begin{array}{l}\text { Dependent variable: } \\
\text { Year: }\end{array}$} & \multicolumn{5}{|c|}{$\log ($ bilateral trade $)$} \\
\hline & $\begin{array}{c}{[1]} \\
2004\end{array}$ & $\begin{array}{c}{[2]} \\
2005\end{array}$ & $\begin{array}{c}3] \\
2006\end{array}$ & $\begin{array}{c}{[4]} \\
2007\end{array}$ & $\begin{array}{c}{[5]} \\
2008\end{array}$ \\
\hline$N_{o d}$ & $\begin{array}{c}1.880^{* * *} \\
(0.593)\end{array}$ & $\begin{array}{c}1.051^{*} \\
(0.593)\end{array}$ & $\begin{array}{c}0.269 \\
(0.648)\end{array}$ & $\begin{array}{c}1.342^{* *} \\
(0.601)\end{array}$ & $\begin{array}{c}1.303^{* *} \\
(0.584)\end{array}$ \\
\hline$N_{o d} M_{d}$ & $\begin{array}{c}-0.922^{* * *} \\
(0.310)\end{array}$ & $\begin{array}{c}-0.788^{* * *} \\
(0.290)\end{array}$ & $\begin{array}{c}-0.587^{*} \\
(0.314)\end{array}$ & $\begin{array}{c}-0.819^{* *} \\
(0.362)\end{array}$ & $\begin{array}{c}-0.585^{+} \\
(0.362)\end{array}$ \\
\hline$N_{o d} L_{d}$ & $\begin{array}{c}0.924 \\
(0.720)\end{array}$ & $\begin{array}{c}2.064^{* * *} \\
(0.709)\end{array}$ & $\begin{array}{c}2.240^{* * *} \\
(0.831)\end{array}$ & $\begin{array}{c}1.616^{* *} \\
(0.710)\end{array}$ & $\begin{array}{c}1.312 \\
(0.940)\end{array}$ \\
\hline$N_{o d} L_{d} M_{d}$ & $\begin{array}{c}1.056^{* * *} \\
(0.349)\end{array}$ & $\begin{array}{c}1.231^{* * *} \\
(0.376)\end{array}$ & $\begin{array}{c}1.193^{* * *} \\
(0.397)\end{array}$ & $\begin{array}{c}1.339^{* * *} \\
(0.411)\end{array}$ & $\begin{array}{c}1.118^{* * *} \\
(0.394)\end{array}$ \\
\hline Control variables included & yes & yes & yes & yes & yes \\
\hline Destination and origin FE & yes & yes & yes & yes & yes \\
\hline Observations & 5,433 & 5,452 & 6,026 & 5,619 & 5,663 \\
\hline R-squared & 0.681 & 0.692 & 0.685 & 0.697 & 0.689 \\
\hline \multicolumn{6}{|c|}{ Marginal effect of $M_{d}$ on $\ln$ imports from neighbors for $A_{d}=0$} \\
\hline If $L_{d}=0$ & $-0.922^{* * *}$ & $-0.788 * * *$ & $-0.587^{*}$ & $-0.819^{* *}$ & $-0.585^{+}$ \\
\hline If $L_{d}=1$ & 0.134 & $0.443^{+}$ & $0.606^{* *}$ & $0.520^{* *}$ & $0.533^{* *}$ \\
\hline
\end{tabular}

Note: This table shows OLS regressions to estimate the impact of mining in both landlocked and coastal destination countries on relative trade with neighboring countries. Variables 2-4 are interactions: $\boldsymbol{N}_{\boldsymbol{o d}}=$ neighbor dummy; $\boldsymbol{M}_{\boldsymbol{d}}=$ a measure of mines in the destination country (in $\left.\ln +1\right) ; \boldsymbol{A}_{\boldsymbol{d}}=\ln$ land area, deviation from world average; $\boldsymbol{L}_{\boldsymbol{d}}=$ landlocked destination dummy. Origin and destination fixed effects are included, and so are the controls listed in Table 5. Robust standard errors in parentheses: ${ }^{* * *} \mathrm{p}<0.01,{ }^{* *} \mathrm{p}<0.05,{ }^{*} \mathrm{p}<0.1{ }^{+} \mathrm{p}=0.12$. Sample: all bilateral trade flows in which the destinations country is in Africa. 


\section{A Appendix}

\section{A.1 Identification of points $S_{j}$ and $P$ and construction of the mine impact index}

The GSHHSD database ${ }^{49}$ used for points $S_{j}$ provides the co-ordinates of all coastlines in the world, and comes in four levels of detail $(1=$ land, $2=$ lake, $3=$ island in lake, $4=$ pond in island in lake) and five resolutions. For our purposes, it is best to use level 1, which excludes the possibility that we find $S$ on the shore of a lake, and a low resolution, which builds up the world's coastlines from 64,000 coordinates. ${ }^{50}$

To identify point $P$, we proceed in several steps. First, we use the "World Port Ranking 2009" provided by the American Association of Port Authorities (AAPA) to infer the main container port for all countries with at least one port included in the ranking. For countries that are not included in the AAPA ranking, we use, when possible, Maersk's website, to track the port used by Maersk Line - the world's leading container shipping company - to import a container from Shanghai into the country's capital. ${ }^{51}$ Finally, for countries that are neither included in the AAPA ranking nor reached by Maersk Line, we identify the main commercial port by conducting a series of internet searches. ${ }^{52}$ We coded as "port co-ordinates" those of the port's nearest city, which we got from the World Urbanization Prospects database, and, for smaller cities, from Wikipedia/GeoHack.

We use MapQuest's online digital maps to calculate distances and routes. ${ }^{53}$ Specifically, we use MapQuest's Directions Web Service (http://www.MapQuestapi.com/directions/). For each pair of locations we send the coordinates to the server, which returns a route along roads as a string of shapepoints (coordinates) and travel distance. We use the shapepoints of the city-port route to find the point on this route that is closest to the mine in a straight line. We then use

\footnotetext{
${ }^{49}$ http://www.ngdc.noaa.gov/mgg/shorelines/gshhs.html

${ }^{50} \mathrm{An}$ intermediate level of detail would use 380,000 coordinates, and quickly increase the time it takes to calculate distances.

${ }^{51}$ Maersk Line has the largest market share (18\%) according to http://www.shippingcontainertrader.com/facts.shtml.

${ }^{52}$ This led us to take Shanghai as the reference port for Kyrgystan, Tajikistan and Mongolia, Poti for Turmenistan and Uzbekistan, and St Petersburg for Kazakhstan.

${ }^{53}$ We chose MapQuest rather than for example Google Maps, because the former's servers allowed access to more routing requests per day. For the Africa and Colony sample we need to construct 13,463 individual indices, requiring more than 5 routing requests each, while the MapQuest daily limit is 5,000. The large number of mines and cities in non-colony countries requires several orders of magnitude additional routing requests. For example, the US would require at least $5^{*} 56^{*} 14,090=3,945,200$ requests for 56 cities and 14,090 mines, which would take more than two years.
} 
that point to find a route and distance along roads from the mine to the city-port route. ${ }^{54}$

The index is constructed as follows. Consider mine $M_{j}$ in destination country $d$. Take a city $C_{i}$ in this country, as well as the country's main container port, $P$. We use MapQuest to find the shortest route along roads connecting $C_{i}$ to $P, C_{i} P$. The city, port and shortest route connecting them are represented in each of the four panels of Figure 5. For illustrative purposes we have represented $C_{i} P$ (and other road connections to be discussed below) as a straight line but this does not need to be the case in the data. We then construct an index measuring the extent to which $M_{j} S_{j}$ overlaps with $C_{i} P$. Because $P$ is the country's main container port, we expect most of the goods imported by $C_{i}$ from overseas countries to be channeled through $C_{i} P$. Our logic is that the more $M_{j} S_{j}$ overlaps with $C_{i} P$ - the higher is the index - the more the mine-to-coast infrastructure will reduce the cost for the country to import from overseas countries.

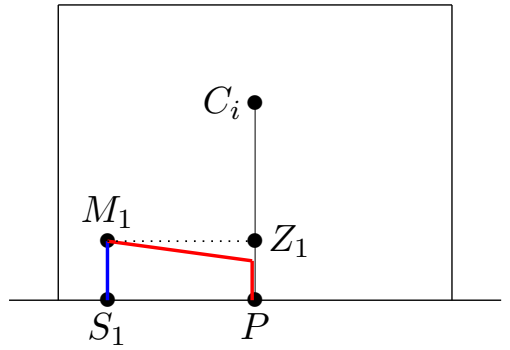

$i_{i j}^{1}=0.3, i_{i j}^{2}=0.8, i_{i j}^{3}=0.35 ; I_{i j}=\mathbf{0 . 0 8}$

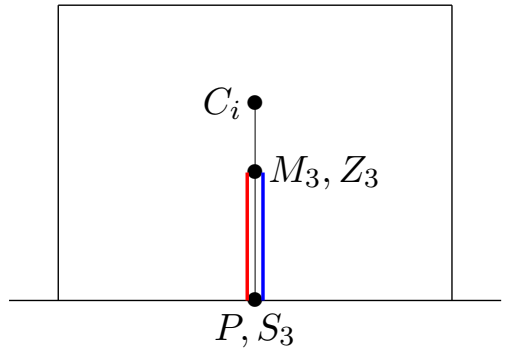

$i_{i j}^{1}=1.0, i_{i j}^{2}=1.0, i_{i j}^{3}=0.7 ; I_{i j}=\mathbf{0 . 7 0}$

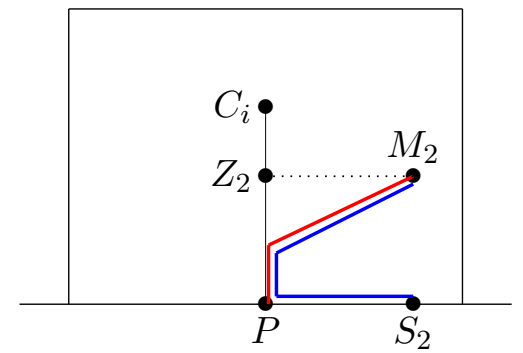

$i_{i j}^{1}=1.0, i_{i j}^{2}=0.6, i_{i j}^{3}=0.7 ; I_{i j}=\mathbf{0 . 4 2}$

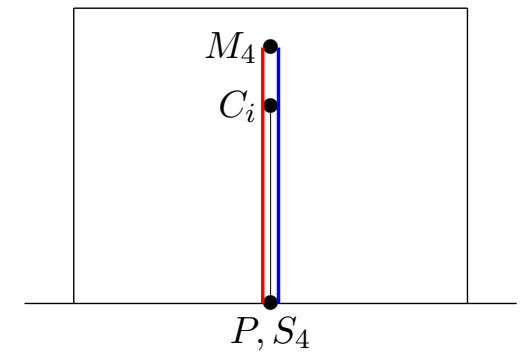

$i_{i j}^{1}=1.0, i_{i j}^{2}=1.0, i_{i j}^{3}=1.0 ; I_{i j}=\mathbf{1 . 0 0}$

Figure 5: Construction of the mine impact index.

\footnotetext{
${ }^{54}$ In some cases the server could not calculate a route because the coordinates of the mine were in a remote location with few roads nearby. In that case (private) access roads to the mine may not appear in the database. In those cases we used the Google reverse geocoding service (https://developers.google.com/maps/documentation/ geocoding/\#ReverseGeocoding) to find the geographical name (of the nearest town one level above street name) of the location of the mine. Using this name we retrieved new coordinates using Google's geocoding service, which were subsequently used to calculate a new route. To the resulting distance we add the straight line distance between $M_{j}$ and the new starting point of the route. If this method still did not yield a route, we instead use the straight-line great circle distance. Mostly, this happened for distances $M S_{j}$ because $S_{j}$ is not necessarily an inhabited location.
} 
Our proposed index for mine $M_{j}$, in relation to city $C_{i}$, is:

$$
I_{i j}=i_{i j}^{1} * i_{i j}^{2} * i_{i j}^{3}
$$

where:

$$
\begin{aligned}
& i_{i j}^{1}=\left\{\begin{array}{lll}
\frac{M_{j} S_{j}+1}{M_{j} P+1} & \text { if } & M_{j} S_{j}<M_{j} P \\
1 & \text { if } & M_{j} S_{j}>M_{j} P
\end{array}\right. \\
& i_{i j}^{2}=\left\{\begin{array}{lll}
\frac{M_{j} P+1}{M Z_{j}+Z_{j} P+1} & \text { if } & Z_{j} P<C_{i} P \\
\frac{M_{j} P+1}{M C_{j}+C_{i} P+1} & \text { if } & Z_{j} P>C_{i} P
\end{array}\right. \\
& i_{i j}^{3}=\left\{\begin{array}{lll}
\frac{Z_{j} P+1}{C_{i} P+1} & \text { if } & Z_{j} P<C_{i} P \\
1 & \text { if } & Z_{j} P>C_{i} P .
\end{array}\right.
\end{aligned}
$$

The mine impact index is the product of three distinct terms, all ranging between 0 and $1 .{ }^{55}$ The first term $\left(i_{i j}^{1}\right)$ compares the length of $M_{j} S_{j}$ to $M_{j} P$ and captures the probability that the mine uses $P$ to export. The term is high when $S_{j}$ is close to $P$ or when $S_{j}$ is far from $P$ but $M_{j} S_{j}$ still follows a large share of $M_{j} P$. In that case $M_{j}$ is naturally positioned to use $P$ as a shipping port. Figure 5 provides an example. The figure contains four panels, each representing a mine, its mine-to-coast infrastructure (in blue) and the shortest route connecting the mine to $P$ (in red). The term $i_{i j}^{1}$ is low (0.3) for mine $M_{1}$ because this mine is located faraway from $P$ and close to the coast and is thus naturally positioned to use a dedicated port. Mine $M_{2}$ however, is also faraway from $P$, but the MapQuest query reveals that the actual route for this mine passes through $P$; there is apparently no road connecting $M_{j}$ to $S_{j}$. The term $i_{i j}^{1}$ is then high for mine $M_{2}$. Finally, $i_{i j}^{1}$ is also high for mines $M_{3}$ and $M_{4}$ since $S_{j}$ is close to $P$ for both: they are both naturally positioned to use $P$ as a shipping port.

The second term $\left(i_{i j}^{2}\right)$ compares the length of $M_{j} P$ to the length of the shortest route connecting $M_{j}$ to $P$ passing through point $Z_{j}$ : this term captures the probability that some part of $C_{i} P$ is used by the mine. $Z_{j}$ is defined as the junction between $C_{i} P$, and the perpendicular coming from $M_{j}$. The term $i_{i j}^{2}$ is high for a mine whose shortest connection to $P$ is on the same axis as $C$ 's shortest connection to $P$. In Figure 5 , mine $M_{2}$ has a relatively low value of $i_{i j}^{2}(0.6)$

\footnotetext{
${ }^{55}$ The term $i_{j}^{2}$ actually ranges between $\frac{\sqrt{2} * Z_{j} P+1}{2 * Z_{j} P+1}$ and 1 .
} 
while $M_{3}$ and $M_{4}$ have a high value (1): that is because $M_{2}$ is located far from the axis of $C_{i} P$, whereas $M_{3}$ and $M_{4}$ are located right on it.

The third term $\left(i_{i j}^{3}\right)$ compares the length of $Z_{j} P$ to that of $C_{i} P$. This term is high for a mine whose shortest connection to $P$ overlaps with a large share of $C_{i} P$. In Figure 5 , mines $M_{3}$ and $M_{4}$ both have a high $i_{i j}^{2}$ since they are both close to $C_{i} P$. However $i_{i j}^{3}$ is relatively low for $M_{3}$ (0.7) while it is high for $M_{4}(1)$, because $M_{3}$ overlaps with only a portion of $C_{i} P$ whereas $M_{4}$ overlaps with all of it.

The overall index is highest for mine $M_{4}(1)$ and lowest for mine $M_{1}(0.08)$. The route from the mine to the coast of the former perfectly overlaps with $C_{i} P$, whereas that of the latter does not overlap with it at all.

In some cases we find that $C_{i}$ very far from $P_{i}$, but also relatively close to a coast. For these particular cities the main container port may not be the relevant one. Such a city may be supplied through a smaller secondary port, which also means that the mine-city route has little impact on the ability to import through the country's main container port. This occurs for 73 out of 238 cities. Therefore, we multiply (4) by a fourth dummy term:

$$
\text { relevance of port }= \begin{cases}0 & \text { if } \quad C_{i} P>\text { Pcentroid } \wedge C_{i} S_{\text {city }}<\text { Pcentroid } \\ 1 & \text { else. }\end{cases}
$$

Where 'centroid' is the centroid of a country ${ }^{56}$, and $S_{\text {city }}$ is a point on the coast nearest to a city $C_{i}$. A weight of zero is given to individual city-mine indices, where (a) the straight-line great-circle city-port distance is longer than the distance between the port and the centroid of the country, and (b) the distance between the city and the coast is less than the distance between the port and the centroid of the country.

\section{A.2 Defining former colonies}

Our favorite definition of former colony is Head et al. (2010)', refined to exclude those countries that were only colonized by a neighbor. To give an example, our definition excludes most of the former Soviet republics (who were only colonized by the USSR), but not Namibia (who

\footnotetext{
${ }^{56}$ From http://www.cepii.fr/anglaisgraph/bdd/distances.htm
} 
Table A.1: Non-African, non-island former colonies.

\begin{tabular}{llll}
\hline Asia & & America & Europe \\
\hline Afghanistan & Kuwait & Belize & Albania \\
Armenia (Russia) & Kyrgyzstan (Russia) & Canada & Bosnia \& Herzegovina \\
AZERAIJAN (Russia) & Laos & French Guiana & BULGARIA (Turkey) \\
Bangladesh & Lebanon & Grenada & Croatia (Austria) \\
BELARUS (Russia) & Macao & Guyana & CZECH REPUBLIC (Austria) \\
Brunei Darussalam & Malaysia & Suriname & Estonia \\
Cambodia & Myanmar & & FINLAND (Russia, Sweden) \\
GEORGIA (Russia) & Pakistan & Gibraltar \\
Hong Kong & Papua New Guinea & & IRELAND (Britain) \\
India & Qatar & & LATVIA (Russia) \\
Indonesia & Syria & & LITHUANIA (Russia) \\
Iraq & Tajikistan (Russia) & & Macedonia \\
Israel & Turkmenistan & Moldova \\
Jordan & UKRAINE (Russia) & & POLAND (Germany) \\
MONGOLIA (China) & United Arab Emirates & & Romania \\
North Korea & Uzbekistan (Russia) & & SLOVAKIA (Austria) \\
South Korea & Viet Nam & SLOVENIA (Austria) \\
KAZAKHSTAN (Russia) & Yemen & & \\
\hline
\end{tabular}

Note: non-African, non island former colonies who obtained independence after 1900. "Non-islands" are countries who share a land border with at least another country. In capital letter are countries whose colonizers were all neighbors (reported in parenthesis). Underlined are countries that, even though their colonizers (reported in parenthesis) where not all neighbors, can still be expected to have traded with all their colonizers mostly overland.

was colonized in different periods both by a neighbor, South Africa, and by a non-neighbor, Germany). For robustness, we have run all our specifications using both the broader Head et al. (2010) definition, as well as a third, even narrower definition. In the latter, we have excluded not only countries who were only colonized by a neighbor, but also those who, despite being colonized by a non-neighbor, can reasonably be expected to have traded with their colonizer overland (e.g. Kyrgyzstan, who was colonized by the USSR). Table A.1 provides a full list of non-African, nonisland former colonies. All African countries except for Liberia and Ethiopia are in our preferred definition of colonies. Our preferred definition of colony includes all countries whose name is in lower case in Table A.1; the broader definition includes also countries whose name is in upper case; and the narrower definition excludes countries whose names is underlined. 